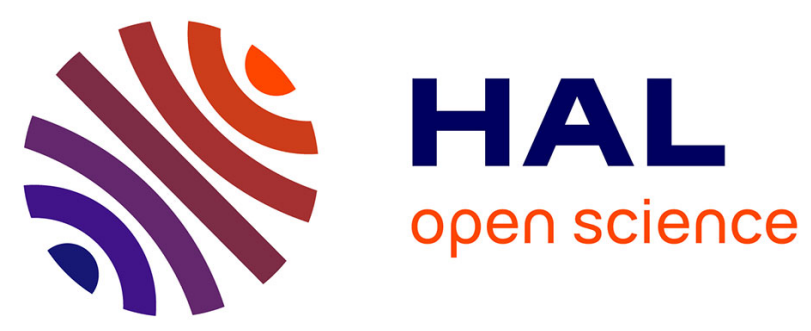

\title{
An intercomparison of measured pressure-broadening, pressure shifting parameters of carbon dioxide and their temperature dependence
}

\author{
Robert R. Gamache, Julien Lamouroux, Valérie Blot-Lafon, Eldon Lopes
}

\section{To cite this version:}

Robert R. Gamache, Julien Lamouroux, Valérie Blot-Lafon, Eldon Lopes. An intercomparison of measured pressure-broadening, pressure shifting parameters of carbon dioxide and their temperature dependence. Journal of Quantitative Spectroscopy and Radiative Transfer, 2014, 135, pp.30-43. 10.1016/J.JQSRT.2013.11.001 . hal-00990428

\section{HAL Id: hal-00990428}

\section{https://hal-univ-rennes1.archives-ouvertes.fr/hal-00990428}

Submitted on 13 May 2014

HAL is a multi-disciplinary open access archive for the deposit and dissemination of scientific research documents, whether they are published or not. The documents may come from teaching and research institutions in France or abroad, or from public or private research centers.
L'archive ouverte pluridisciplinaire HAL, est destinée au dépôt et à la diffusion de documents scientifiques de niveau recherche, publiés ou non, émanant des établissements d'enseignement et de recherche français ou étrangers, des laboratoires publics ou privés. 
An intercomparison of measured pressure-broadening, pressure shifting parameters of carbon dioxide and their temperature dependence

Robert R. Gamache ${ }^{\dagger a}, J_{\text {Jien Lamouroux }}^{a, b}$, Valérie Blot-Lafon ${ }^{\mathrm{c}}$, Eldon Lopes ${ }^{\mathrm{a}}$

${ }^{a}$ Department of Environmental, Earth, and Atmospheric Sciences

University of Massachusetts Lowell

One University Avenue

Lowell, MA 01854, USA

${ }^{\mathrm{b}}$ current address

Laboratoire Interuniversitaire des Systèmes Atmosphériques (LISA)' CNRS UMR 7583, Universités Paris Est Créteil et Paris Diderot, Institut Pierre-Simon Laplace. Université Paris Est Créteil, 94010 Créteil Cedex, FRANCE

${ }^{\mathrm{c}}$ Department of Physics

Université de Rennes 1

F-35042 Rennes Cedex, FRANCE 
$\dagger$ Corresponding author

Robert_Gamache@uml.edu

978-934-3904 
Abstract:

An intercomparison of measured pressure-broadening and pressure-shifting coefficients for carbon dioxide absorption lines was done. The work focuses on collision systems where a significant number of data can be found $\left(\mathrm{CO}_{2}-\mathrm{N}_{2}, \mathrm{CO}_{2}-\mathrm{O}_{2}, \mathrm{CO}_{2}\right.$-air, and $\mathrm{CO}_{2}-\mathrm{CO}_{2}$ ) and yield information important to applications to Earth's atmosphere. The literature was searched for measured line shape parameter data for the collision systems mentioned above. Databases were created for each perturbing gas with the ro-vibrational transition as the key. Using these databases, intercomparisons of the measurements of half-widths, their temperature dependence, and line shifts were made. The data allow the investigations of trends in the data with respect to the vibrational and the rotational quantum numbers, various line shape models, and isotopologue effects.

The data were averaged and an estimated uncertainty determined. The averaged data sets are evaluated with respect to the need of the spectroscopic and remote sensing communities. In general many data points do not agree within the stated uncertainty estimate independent of the broadening species. Agreement between measurements of the temperature dependence of the half-width is in a poor state and the understanding of the temperature dependence of the line shift is in its infancy. The intercomparison data show more measurements are needed for the $\mathrm{CO}_{2}-\mathrm{O}_{2}, \mathrm{CO}_{2}-\mathrm{N}_{2}$ and $\mathrm{CO}_{2}-\mathrm{CO}_{2}$ systems. In addition to the half-width at $296 \mathrm{~K}$, data are needed for the temperature dependence of the half-width and line shift.

Keywords: $\mathrm{CO}_{2}$, measured half-widths, line shifts, temperature dependence of half-width and line shift 


\section{INTRODUCTION}

Carbon dioxide is a trace gas in the Earth's atmosphere with a concentration of $0.039445 \%$ [1]. Even with this seemingly low mixing ratio it is the second strongest absorber of infrared radiation in the Earth's atmosphere after water vapor [2]. $\mathrm{CO}_{2}$, however, has a residence time of about 120 years in the atmosphere compared to water vapor which has a residence time of $\sim 9$ days. Because of its long lifetime, $\mathrm{CO}_{2}$ is evenly mixed in the atmosphere. Due to these facts carbon dioxide has become the standard by which other greenhouse gases are gauged in global climate change. The mixing ratio of $\mathrm{CO}_{2}$ is being monitored daily and records of direct measurement go back to $1957[3,4]$. Proxy methods allow the records to be extended back hundreds of thousands of years [5]. The current concentration of $394 \mathrm{ppm}$ is larger than it has been in the last 650 thousand years $[5,6]$ and probably much longer. Recent proxy data show an abrupt rise in the $\mathrm{CO}_{2}$ concentration after the industrial revolution and this increase is thought to be of anthropogenic origin [7].

It is paramount that the role of $\mathrm{CO}_{2}$ in global climate change is better understood. As such the international community is actively monitoring the sources and sinks of $\mathrm{CO}_{2}$ globally. Measurements are being made from ground-based networks [8], from balloons $[9,10]$, and from a number of satellite platforms. NASA's AQUA satellite [11] has the Atmospheric Infrared Sounder (AIRS) [12] and the METOP-A satellite [13] has the Infrared Atmospheric Sounder Interferometer (IASI) [14] both measuring in the midinfrared region. In 2009 the Greenhouse Gases Observing Satellite (GOSAT) [15] was launched by Japan to make measurements of carbon dioxide in the $1.6 \mu \mathrm{m}$ and $2 \mu \mathrm{m}$ region. The Jet Propulsion Laboratory attempted to launch the Orbiting Carbon 
Observatory [16] in 2009 but the satellite failed to reach orbit. The importance of the mission [17] has prompted NASA to go forward with the launch of OCO-2 in the 20132014 time frame. The OCO-2 mission will require mixing ratios be retrieved with a precision of $0.3 \%$ placing strong demands on the spectroscopic community [18]. Miller et al. [18] state that the OCO remote sensing precision requirements for the Lorentz broadened half-width and line shift are $0.6 \%$ and $<0.0002 \mathrm{~cm}^{-1}$ atm$^{-1}$ respectively. This requirement is for air- $\mathrm{CO}_{2}$ thus in this work the $0.6 \%$ precision level is applied to $\mathrm{N}_{2-}$, $\mathrm{O}_{2-}$, and air- $\mathrm{CO}_{2}$ mixtures. While self-broadening of $\mathrm{CO}_{2}$ in the Earth's atmosphere is negligible (Note, self-broadening is the dominant contribution in some planetary atmospheres.) the same precision requirement is used to be consistent with the other broadeners. They also point out that line shape models more accurate than the Voigt model are needed.

Of the spectroscopic parameters, it is the line shape parameters that are the least well known and while the shift can affect retrievals [19-22] the half-width has a stronger effect in retrievals from atmospheric spectra [23-26] reaching 1:1, error in the half-width to error in the retrieval, at surface pressures. This work presents an intercomparison of the measured half-widths and line shifts of carbon dioxide important for terrestrial applications. This study was undertaken to assess the state of knowledge of measurements of the line shape parameters for $\mathrm{CO}_{2}$ and to address if the needs of the remote sensing community can be satisfied. These data allow an understanding of the influence of vibration, $\mathrm{J}$ dependence of the broadening, shifting, and temperature dependence, different collision partners, different line shape models, and broadening for different isotopologues. The intercomparison will allow a sense of the uncertainty in the 
parameters. These data will point to gaps in the measurement record and suggest measurements that are crucially missing in order to complete a selected set of data. These data were also used to identify measurements that could be used to test the theoretical models.

Section 2 discusses the collection of the experimental results and the creation of the databases. Section 3 reports the analysis of the data including the dependence of the collision-induced parameters on vibration, rotation, temperature, broadening partner, and line shape models. Intercomparisons of the data are also discussed in this section. In section 4 , conclusions and recommendations are made.

\subsection{THE EXPERIMENTAL RESULTS}

This work considers the collision-broadened half-widths and pressure induced line shifts of carbon dioxide for terrestrial applications. A search of the literature was made for line shape parameters for the $\mathrm{CO}_{2}-\mathrm{N}_{2}, \mathrm{CO}_{2}-\mathrm{O}_{2}, \mathrm{CO}_{2}$-air, $\mathrm{CO}_{2}-\mathrm{CO}_{2}$ collision systems. The result was 87 papers from 1968 to 2012 [22, 27-112]. Most of the work focused on measurements of the pressure-broadened half-width with $33,13,24$, and 48 papers, respectively, reporting data on $\mathrm{N}_{2^{-}}, \mathrm{O}_{2^{-}}$, air-, and self-broadening of $\mathrm{CO}_{2}$. The first measurements of the pressure-induced line shift for $\mathrm{CO}_{2}$ were reported in 1998. The number of papers reporting measurements of the pressure-induced line shift drops to 9,3 , 11, and 12 for the perturbers respectively. Considering the temperature dependence of the half-width the number of papers drops further with $9,3,4$, and 4 for $\mathrm{N}_{2^{-}}, \mathrm{O}_{2^{-}}$, air-, and self-broadening of $\mathrm{CO}_{2}$. The temperature dependence of the line shift has only 
recently been studied with 2 papers each for the air- and self-collision systems. A small number of papers (8) report measurements on the lesser isotopologues of $\mathrm{CO}_{2}$ $\left({ }^{16} \mathrm{O}^{13} \mathrm{C}^{16} \mathrm{O},{ }^{16} \mathrm{O}^{12} \mathrm{C}^{18} \mathrm{O}\right.$, and $\left.{ }^{16} \mathrm{O}^{13} \mathrm{C}^{18} \mathrm{O}\right)$. The data also allow the vibrational dependence of these line shape parameters to be considered with measurements available for 17 $\left(\mathrm{CO}_{2}-\mathrm{N}_{2}\right), 8\left(\mathrm{CO}_{2}-\mathrm{O}_{2}\right), 17\left(\mathrm{CO}_{2}\right.$-air), and $37\left(\mathrm{CO}_{2}-\mathrm{CO}_{2}\right)$ vibrational bands. Tables 1-4 present a summary of the data for the $\mathrm{CO}_{2}-\mathrm{N}_{2}, \mathrm{CO}_{2}-\mathrm{O}_{2}, \mathrm{CO}_{2}$-air, $\mathrm{CO}_{2}-\mathrm{CO}_{2}$ collision systems respectively. These tables list the maximum J" value, the number of data for the half-width, $n_{r}$, the line shift, $n_{\diamond}$, and the temperature dependence of the half-width, $n_{\mathrm{n}}$, the minimum and maximum values of $\gamma, \delta$, and $n$ as a function of isotopologue and vibrational band. The notation of the vibrational quantum numbers in the Table is that of Toth et al. [113].

Approximate position of Tables 1-4

The data in Tables 1-4 show that half-widths change by a factor of 2.01, 1.8, 2.2, and 6.4 for $\mathrm{N}_{2^{-}}, \mathrm{O}_{2^{-}}$, air- and self-broadening respectively. As an example, the airbroadened value can be compared with that for water where the half-widths change by a factor of 44 [114]. As a function of J", the half-widths increase at very low J" values and then as $\mathrm{J}$ " increases the half-widths decrease. The line shifts are mostly negative in the database files. For example the $\mathrm{CO}_{2}-\mathrm{N}_{2}$ collision system has a few positive values for transitions to low energy vibrational states. One of these values is much larger than the others and may be erroneous. Similar problems may arise looking at the maximum values of the temperature exponent for $\mathrm{N}_{2^{-}}, \mathrm{O}_{2^{-}}$, and self-broadening. In the study by 
Predoi-Cross et al. [68] the air-broadening $n$ values ranged from roughly 0.65 to 0.89 . Theoretical calculations by Gamache et al. [115-117] for the 4 broadeners of this study show $\mathrm{n}<0.8$. Caution should be exercised when using values greater than 1.0.

Tables 1-4 lists the vibrational bands that have been studied for the different $\mathrm{CO}_{2}$ collision systems. The table shows that the maximum number of $v_{1}, v_{2}$, and $v_{3}$ quanta exchanged in the ro-vibrational transitions that have been measured are small; $\Delta v_{1 \max }$, $\Delta v_{2 \max }$, and $\Delta v_{3 \max }$ are 2, 4, and 3 for $\mathrm{N}_{2}$-broadening; 2, 4, and 1 for $\mathrm{O}_{2}$-broadening; 2 , 4, and 3 for air-broadening; and 3, 4, and 3 for self-broadening.

To account for the various collisional effects observed for $\mathrm{CO}_{2}$ at different experimental conditions a number of different line shape models have been used to reduce the measured spectra. For a review of the various models see the work of Hartmann et al. [118] and references therein. Table 5 gives the line shape models used to fit the spectra and an index labeling the model in the database. The results from these models are discussed below.

Approximate position of Table 5

These data have been organized into databases for each perturbing gas with the values corrected, when necessary, to $296 \mathrm{~K}$. The format is similar to that of the line shape parameter databases for water $[114,119]$ or ozone [120] with modifications for the quantum numbers and an index for the line shape model used in the reduction of the measured data. 
3.0 Intercomparison of the data

3.1 Intercomparison of the collision-induced parameters

The database files for each collision system were taken and sorted to group transitions with the same quantum numbers; $\mathrm{v}_{1}$ ' $\mathrm{v}_{2}$ ' $\mathrm{v}_{3}$ 'J' $\leftarrow \mathrm{v}_{1}$ " $\mathrm{v}_{2}$ " $\mathrm{v}_{3}$ "J". These data appear in groups of 2-9 points. The half-width data were compared to each other (intercomparison) by determining the average percent difference (APD),

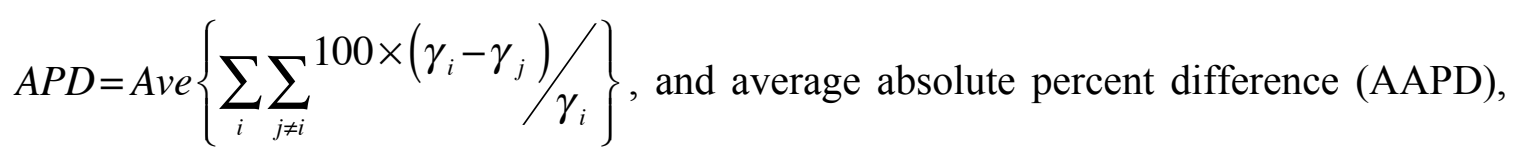
$A A P D=A v e\left\{\sum_{i} \sum_{j \neq i} A b s\left[100 \times\left(\gamma_{i}-\gamma_{j}\right) / \gamma_{i}\right]\right\}$, by comparing points I and $\mathrm{J}$ where $\mathrm{I}=1$ to $\mathrm{N}, \mathrm{J}=\mathrm{I}+1$ to $\mathrm{N}$ and $\mathrm{I} \neq \mathrm{J}$, where $\mathrm{N}$ is the number of intercomparison points. For the line shifts the APD and AAPD were calculated however due to comparing small numbers many of the values are large. As an alternative the average absolute ratio, $A R=A v e\left\{\sum_{i} \sum_{j \neq i} \frac{\delta_{i}}{\delta_{j}}\right\}$, of the data were taken. Table 6 lists the number of points in the intercomparison, $n_{i}$, the number of transitions with $n_{i}$, the APD, AAPD, and AR. This table clearly shows the lack of data for the $\mathrm{CO}_{2}-\mathrm{O}_{2}$ system. In general the APDs range from $\sim 0.2$ to $3 \%$ and the AAPDs from $\sim 2$ to $6 \%$. The ARs vary considerably from 0.65 for the oxygen-induced shift to 2.27 for air-induced shift with $n_{l}=3$. These differences are more apparent in the plots. Figures 1-2 and 3-4 show example plots for the half-widths and line shifts for $\mathrm{CO}_{2}-\mathrm{N}_{2}$ (Figs. 1-2) and $\mathrm{CO}_{2}-\mathrm{CO}_{2}$ (Figs. 3-4) collision systems respectively. 
Approximate position of Table 6

Approximate position of Figs 1-4

\subsection{Effects of rotational transition}

There are a number of measured data sets, each for a particular vibrational band, that contain a sufficient number of transitions to address the effect of the rotational transition on the line shape parameters. Figure 5a-c present the measured half-width, line shift, and temperature dependence of the half-width as a function of $m$, where $m=-\mathrm{J}$ ", J" +1 for P- and R-branch transitions, respectively for the $30012 \leftarrow 00001$ band of $\mathrm{CO}_{2}$ in collision with $\mathrm{N}_{2}$; note measurements go to $|m| \approx$ mid sixties. In general the data show the half-width decreases as $|m|$ increases. This structure is true for the other perturbers studied here. A similar structure is observed for the line shift with the shift becoming more negative as $|m|$ increases. The temperature dependence of the half-width decreases with some oscillation as seen in the plot. Note, this structure is evident even considering the scatter in the data. Recent theoretical work for the $\mathrm{CO}_{2}-\mathrm{N}_{2}, \mathrm{CO}_{2}-\mathrm{O}_{2}, \mathrm{CO}_{2}$-air, and $\mathrm{CO}_{2}-\mathrm{CO}_{2}$ systems [115-117], which demonstrates excellent agreement with measured half-widths, line shifts, and temperature dependence of the line shift, shows similar plots with calculations to $|m|=120$. Complete sets of measurement plots are available on the web site of one of the authors (faculty.uml.edu/Robert_Gamache).

Approximate position of Fig. 5 


\subsection{Effects of vibration}

The number of vibrational transitions observed varies with the particular perturber, see Tables 1-4 for details. There are no experimental studies of the vibrational dependence of the half-width that have been both systematic and comprehensive. A good number of papers have been published addressing the vibrational dependence of the halfwidth within confined spectral regions. It is difficult to draw any firm conclusions from these studies. A number of papers $[22,35,36,48,52-55,64,66,107,108]$ report that the vibrational dependence of the half-width is very small; "within the error bars." Several studies report a measurable vibrational dependence in $\mathrm{CO}_{2}$ self-broadened half-widths $[64,71]$. There are also studies that contradict one another; for example Young and Chapman [106] report half-widths in the $9.4 \mu \mathrm{m}$ band are 5\% smaller than those in the 10. $4 \mu \mathrm{m}$ band whereas Moskalenko and Zotov [121] state half-widths in the $9.4 \mu \mathrm{m}$ band are $5 \%$ larger than those in the $10.4 \mu \mathrm{m}$ band.

In a recent theoretical work on the vibrational dependence of half-widths and line shifts of $\mathrm{CO}_{2}$ transitions, Gamache and Lamouroux [122] noted that in the above analyses most of the comparisons are for vibrational bands within the same polyad or between bands that have roughly the same number of vibrational quanta exchanged. In their study they began with the expression for the vibrational dependence of $\gamma$ and $\delta$ developed by Gamache and Hartmann [123] and modified the expressions for a study of the vibrational dependence of $\gamma$ and $\delta$ of $\mathrm{CO}_{2}$ transitions giving,

$$
\gamma\left[\left(v_{1}^{\prime}, v_{2}^{\prime}, v_{3}^{\prime}\right) f \leftarrow\left(v_{1}^{\prime \prime}, v_{2}^{\prime \prime}, v_{3}^{\prime \prime}\right) i\right]=I_{f \leftarrow i}^{\gamma}+A_{f \leftarrow i} a b s\left(c_{1}\left|\Delta v_{1}\right|+c_{2}\left|\Delta v_{2}\right|+c_{3}\left|\Delta v_{3}\right|\right)^{\mathrm{p}_{\gamma}}
$$




$$
\delta\left[\left(v_{1}^{\prime}, v_{2}^{\prime}, v_{3}^{\prime}\right) f \leftarrow\left(v_{1}^{\prime \prime}, v_{2}^{\prime \prime}, v_{3}^{\prime \prime}\right) i\right]=I_{f \leftarrow i}^{\delta}+B_{f \leftarrow i} a b s\left(c_{1}\left|\Delta v_{1}\right|+c_{2}\left|\Delta v_{2}\right|+c_{3}\left|\Delta v_{3}\right|\right)^{\mathrm{p}_{\delta}}
$$

where $\gamma$ and $\delta$ are the half-width and line shift for the ro-vibrational transition $\left(v_{1}^{\prime}, v_{2}^{\prime}, v_{3}^{\prime}\right) f \leftarrow\left(v_{1}^{\prime \prime}, v_{2}^{\prime \prime}, v_{3}^{\prime \prime}\right) i, I_{f \leftarrow i}^{\gamma}$ and $I_{f \leftarrow i}^{\delta}$ are the intercepts and $A_{\mathrm{f}_{\leftarrow} \mathrm{i}}$ and $B_{\mathrm{f}_{\leftarrow} \mathrm{i}}$ are the slopes both with units of $\mathrm{cm}^{-1} \mathrm{~atm}^{-1}$, and $\left(c_{1}\left|\Delta v_{1}\right|+c_{2}\left|\Delta v_{2}\right|+c_{3}\left|\Delta v_{3}\right|\right)^{\mathrm{p}_{\gamma}}$ and $\left(c_{1}\left|\Delta v_{1}\right|+c_{2}\left|\Delta v_{2}\right|+c_{3}\left|\Delta v_{3}\right|\right)^{\mathrm{p}_{\delta}}$ are the Quantum Coordinates of the lines describing the vibrational dependence of the half-widths and line shifts respectively. These expressions fit the calculated data very well $\left(<5 \times 10^{-4} \mathrm{~cm}^{-1} \mathrm{~atm}^{-1}\right.$ for $\gamma$ and $<1.5 \times 10^{-3} \mathrm{~cm}^{-1} \mathrm{~atm}^{-1}$ for $\left.\delta\right)$ and allow prediction of the line shape parameters for any ro-vibrational transition of $\mathrm{CO}_{2}$ [124]. They also explain why the studies within a polyad should not show appreciable vibrational dependence.

Studying the vibrational dependence of the half-width and line shift from the measurement data allows changes in vibrational quanta up to $\Delta v_{1}=3, \Delta v_{2}=6, \Delta v_{3}=3$ (see Tables 1-4 for details). Here, plots of $\gamma$ or $\delta$ versus the appropriate Quantum Coordinate were made for each collision system, $\mathrm{CO}_{2}-\mathrm{X}$ with $\mathrm{X}=\mathrm{N}_{2}, \mathrm{O}_{2}$, air, and $\mathrm{CO}_{2}$. Figures 6 and 7 show examples for the P18 line of $\mathrm{CO}_{2}$ broadened by air and the $\mathrm{R} 20$ line of $\mathrm{CO}_{2}$ selfbroadened. Plotted are the half-widths and line shifts with the error bars versus the quantum coordinate. Also shown in the plots are the predicted fits of the data from Ref. [124] as the solid black line. What is clear is that there is considerable scatter in the measured values. Many of the data points do not overlap within the quoted errors. The prediction formulas give reasonable descriptions of the measurements. Complete sets of 
plots for all collision systems are available on the web site of one of the authors (faculty.uml.edu/Robert_Gamache).

\section{Approximate position of Figs 6-7}

\subsection{Line shape models}

In an effort to reduce the fit residuals when determining the parameters that describe the spectrum many line shape models have been used. Table 5 shows that, for $\mathrm{CO}_{2}$ as the radiating molecule, eleven line shape models have been employed when fitting spectra. These models, which are more advanced than the Lorentz (or Voigt) model, contain additional fitting parameters, some up to six parameters [125], and always reduce the fit residual. However, it has been shown $[126,127]$ that for some of these models some of the parameters giving the improved fits are unphysical. Figures 1 and 8 show the measured half-widths deduced using different line shape model versus line number. The plot symbols for the different line shape models are given in Table 5. Also shown in the plot is the predicted value [124] as the solid black triangle. The plots show small differences between the half-widths reduced using different line shape models. However, looking at many plots (available online at faculty.uml.edu/Robert_Gamache) the scatter in the data and uncertainties it is difficult to make definitive statements about the effect of the model on the derived half-widths. Luckily, there are a number of studies that applied two line shape models to a number of measured spectra and allow a statement. For example, Refs. $[56,67,105]$ show that their speed-dependent model gives results a few percent higher than the Voigt model, which was also mentioned by Hartmann et al. [118]. 
Note however, there are plots that show one model's results higher than another model in one plot and lower in another.

\section{Approximate position of Fig. 8}

\subsection{Isotopologue effects}

A limited number of half-width measurements are available for several of the isotopologues of the $\mathrm{CO}_{2}$ molecule; ${ }^{12} \mathrm{C}^{16} \mathrm{O}_{2},{ }^{13} \mathrm{C}^{16} \mathrm{O}_{2},{ }^{16} \mathrm{O}^{12} \mathrm{C}^{18} \mathrm{O}$, and ${ }^{16} \mathrm{O}^{13} \mathrm{C}^{18} \mathrm{O}$. A good number of intercomparisons are available for the pair ${ }^{12} \mathrm{C}^{16} \mathrm{O}_{2}$ and ${ }^{13} \mathrm{C}^{16} \mathrm{O}_{2}$, there are also a limited number of comparisons for the pairs ${ }^{12} \mathrm{C}^{16} \mathrm{O}_{2}$ and ${ }^{16} \mathrm{O}^{12} \mathrm{C}^{18} \mathrm{O}$ and ${ }^{12} \mathrm{C}^{16} \mathrm{O}_{2}$ and ${ }^{16} \mathrm{O}^{13} \mathrm{C}^{18} \mathrm{O}$. Theory $[128,129]$ provides a guide to the effects of the mass dependence of the half-width. Assuming all collisions are resonant and a single intermolecular potential term of the form $\mathrm{R}^{-\mathrm{q}}$, the temperature dependence of the half-width in $\mathrm{cm}^{-1} /$ molecule is

$$
\gamma(T) \propto T^{-(q-3) / 2(q-1)}
$$

Because the temperature dependence is essentially due to the mean relative speed $v_{\mathrm{r}}(\mathrm{T})$ in the intermolecular collision, and since $v_{r}(\mathrm{~T})$ is proportional to $\sqrt{T / \mu}$ the following relations hold

$$
\gamma(T) \propto v_{r}(T)^{-(q-3) /(q-1)}
$$

and 


$$
\gamma(T) \propto \mu^{-(q-3) / 2(q-1)}
$$

where $\mu$ is the reduced mass. Note all of the collision systems considered here have the quadrupole-quadrupole interaction as the leading term in the intermolecular potential, i.e. $\mathrm{q}=5$. Thus, knowing the broadening of ${ }^{12} \mathrm{C}^{16} \mathrm{O}_{2}$ by a broadener, the broadening of other isotopologues can be approximated by

$$
\gamma\left({ }^{a} C^{b} O_{2}-X\right)=\gamma\left({ }^{12} C^{16} O_{2}-X\right)\left(\frac{\mu\left({ }^{a} C^{b} O_{2}-X\right)}{\mu\left({ }^{12} C^{16} O_{2}-X\right)}\right)^{-\alpha}
$$

where $\alpha=0.25$.

The calculated isotopologue scaling factor (ratios of the reduced masses raised to the power $-\alpha$ ) are listed in Table 7 for $\mathrm{N}_{2}, \mathrm{O}_{2}$, air, and ${ }^{12} \mathrm{C}^{16} \mathrm{O}_{2}$ as the collision partners. For air the reduced mass was determined using the average molecular weight of dry air, $28.96 \mathrm{~g} / \mathrm{mol}[130]$. The table indicates that the half-widths for the other heavier isotopologues will be slightly smaller that those of ${ }^{12} \mathrm{C}^{16} \mathrm{O}_{2}$, of order less than $1 \%$. Looking at the intercomparison plots there are many where the heavier isotopologue halfwidths are $\sim 1 \%$ smaller, however there is much scatter in the measurement database and the relationship between isotopologues is not always the same. Figure 9 shows the P 34 line of the $00011 \leftarrow 10001$ (top panel) and $00011 \leftarrow 10002$ (bottom panel) bands. Looking at the data for these two bands [22] and comparing the half-width for the ${ }^{13} \mathrm{C}^{16} \mathrm{O}_{2}$ isotopologue to that of the ${ }^{12} \mathrm{C}^{16} \mathrm{O}_{2}$ isotopologue one finds the ${ }^{13} \mathrm{C}^{16} \mathrm{O}_{2}$ value slightly larger for the $00011 \leftarrow 10001$ band and slightly smaller for the $00011 \leftarrow 10002$ band. 
While there are some exceptions this observation generally holds in the data [22], indicating the possibility of a vibrational effect. Looking at the other plots for isotopologues (available at faculty.uml.edu/Robert_Gamache) it is difficult to draw any conclusions due to the scatter in the data. Often there are data points above and below the lesser isotopologue half-widths. The same observation is made for the line shift intercomparisons with respect to the isotopologues.

Approximate position of Fig. 9

\subsection{Temperature dependence of the half-width}

As discussed above, the number of papers that report the temperature dependence of the half-width is relatively small. The temperature dependence of the half-width is expressed using the power law model, see section 3.5, and is generally expressed as

$$
\gamma(T)=\gamma\left(T_{0}\right)\left[\frac{T_{0}}{T}\right]^{n}
$$

where $n$ is the temperature exponent. The use of the power law model has been called into question for certain radiator-perturber collision pairs and for large temperature ranges $[131,132]$ with important considerations for $\mathrm{CO}_{2}$ as the radiating molecule [115117]. Note, the $n$ data from Ref. [37] for $\mathrm{CO}_{2}-\mathrm{N}_{2}$ are unusually large (some values are greater than 2) well outside the range of other measurements or theoretical calculations. 
From the measured data there are no intercomparisons of $n$ for the $\mathrm{CO}_{2}-\mathrm{N}_{2}$ and $\mathrm{CO}_{2}-\mathrm{O}_{2}$ collision systems, there are 4 intercomparisons for the $\mathrm{CO}_{2}$-air collision system, and for the $\mathrm{CO}_{2}-\mathrm{CO}_{2}$ collision system 112 plots were made, however the intercomparisons are of the data from Ref. [68] where two different line shape models, Voigt and speed dependent Voigt, were used. Thus, the intercomparisons are of the line shape models and no conclusion can be drawn from the data as the Voigt model gives $n$ values sometimes a few percent lower and sometimes a few percent higher than the speed dependent model. Considering J" and J' and ignoring vibrational dependence, which is expected to be small (see section 3.3), more intercomparisons are possible. Figure 10 shows measured temperature exponents with the corresponding error bars for the $\mathrm{R} 20$ transition for $\mathrm{CO}_{2}$ $\mathrm{CO}_{2}$ versus the Quantum Coordinate. As before, the plot symbols refer to the line shape model used to reduce the spectra. Note, for the Quantum Coordinate around 0.5 there are 4 data points. These are from Ref. [68] for the $30012 \leftarrow 00001$ and $30013 \leftarrow 00001$ bands using the Voigt and a speed dependent Voigt model. Finally, Fig. 11 shows the temperature exponent versus $m$, where $m$ equals $-J$ ' for $\mathrm{P}-, \quad J$ ' for Q-, and $J$ '+1 for Rbranch transitions. In black are the recent measurements of Predoi-Cross et al. [68] for the $30012 \leftarrow 00001$ and $30013 \leftarrow 00001$ bands. The plot symbols reflect the line shape model used to reduce the data. The scatter in the data is quite noticeable. It appears the comment in the HITRAN article [2] discussing improvements needed in the line shape parameters of ozone, "This especially concerns the temperature exponents where the experimental measurements rarely agree with each other or with the theoretical calculations," also applies to $\mathrm{CO}_{2}$. This observation is not particularly surprising since it has been shown [120] that the uncertainty in the temperature exponent $n$ is related to the 
uncertainty in the half-width and the temperature range used in the measurements. The uncertainties in $n$ in the databases appear to be underestimated, they are generally 1- (or 2-) sigma of the fit and do not include systematic errors or the temperature range of the measurements.

\subsection{CONCLUSIONS AND RECOMMENDATIONS}

A literature search of measured half-widths, line shifts, temperature dependence of the half-widths and line shifts for $\mathrm{CO}_{2}$ in collision with $\mathrm{N}_{2}, \mathrm{O}_{2}$, air, and $\mathrm{CO}_{2}$ has led to the collection of 7087 data points that have been stored in databases. Using these databases intercomparison of the data was done to determine trends in the data, rotational-, vibrational-, isotopologue-, and temperature-dependence. In general many measurements do not agree within the stated uncertainty estimate. Considering measurements made in the past decade the data points still do not agree within the quoted error. The uncertainties reported seem to be one standard deviation of the fit of the line rather than the combined uncertainty accounting for all statistical and systematic uncertainties. Miller et al. [18] state "The multispectrum technique can determine spectrum line half-widths with an uncertainty better than $0.1 \%$, but the systematic uncertainties have always limited the absolute accuracy of half-widths determined from experimental spectra to $1-2 \%$." It is likely that the reported uncertainties often underestimate the actual uncertainties because systematic contributions to measurement uncertainty are not considered. In the future, researchers should report the true error of the measurements. 
The needs of the spectroscopic community, especially the OCO-2 mission, place a heavy burden on measurement. While Table 6 reports averages for the intercomparisons, the data can be studied line by line. For air-broadening only 35 of the transitions out of the 224 intercomparisons have the average absolute difference less than or equal to $0.6 \%$. For $\mathrm{N}_{2^{-}}, \mathrm{O}_{2^{-}}$, and self-broadening there are 21,4 , and 67 transitions out of the 233, 39, and 536 intercomparisons respectively that have an $\mathrm{AAD} \leq 0.6 \%$. In the air-broadened data none of the 35 transitions are in the spectral range of importance to OCO-2. An additional 43 transitions have an APDs between 0.6 and 1 and 137 have APDs between 1 and 5 for air- broadening. Thus there is a need for more measurements of $\mathrm{CO}_{2}$-air mixtures.

To aid theoretical calculations measurements need to be made for single perturbing gases $\left(\mathrm{N}_{2}, \mathrm{O}_{2}, \mathrm{CO}_{2}\right)$ and not mixtures (air). Looking at the databases there is a shortage of half-width measurements for the $\mathrm{CO}_{2}-\mathrm{O}_{2}$ system allowing only 36 2-point and 3 3-point intercomparisons. More high-accuracy measurements of half-widths for the $\mathrm{CO}_{2}-\mathrm{N}_{2}$ and $\mathrm{CO}_{2}-\mathrm{CO}_{2}$ systems would also be useful. While the line shifts are less important to remote sensing they are very useful to gauge the theory. Measurements of the temperature dependence of the half-width are in a poor state as demonstrated by the intercomparisons. More measurements should be done considering larger temperature ranges. Gamache et al. [120] have shown that the uncertainty in the temperature exponent is proportional to the ratio of the uncertainty in the half-width over the halfwidth divided by the natural $\log$ of $T_{\max } / T_{\min }$ (see Appendix A of Ref. [120]). Thus the larger the temperature range the smaller the uncertainty in $n$. 
Measurements of the temperature dependence of the line shift are still in their infancy. In early works by Varanasi and Chudamani [133] and by Grossmann and Browell $[134,135]$ a model similar to that used for the half-width given by

$$
\delta(T)=\delta\left(T_{0}\right)\left[\frac{T_{0}}{T}\right]^{n^{\prime}}
$$

was used. Note, all parameters have their usual meaning. However, as pointed out by Gamache and Rothman [136], and later by Smith et al. [137], this model does not allow the shift to change sign. Frost [138] proposed a model that allows for a change of sign in the line shift modified here to give the shift at temperature $\mathrm{T}$ from the shift at a reference temperature $\mathrm{T}_{0}$ (note the correction of Eq. (5) of Ref. [137])

$$
\delta(T)=\delta\left(T_{0}\right)\left[\frac{T_{0}}{T}\right]^{n^{\prime}}\left[\frac{1+A \ln (T)}{1+A \ln \left(T_{0}\right)}\right]
$$

where $\mathrm{A}$ is a fitted constant which is negative (see Frost for details). Gamache and Rothman [136] proposed a different model that allows for the sign of the shift to change

$$
\delta(T)=\delta\left(T_{0}\right) S\left(T^{\prime}\right)\left[\frac{T_{0}}{T}\right]^{n^{\prime}}
$$


where $\mathrm{S}\left(\mathrm{T}^{\prime}\right)$ changes from -1 to 1 at $\mathrm{T}^{\prime}$. The last two models require fits to obtain the additional parameters. The work of Smith et al. [137, 139-141] suggest their data can be fit by a linear model

$$
\delta(T)=\delta^{0}\left(T_{0}\right)+\delta^{\prime}\left(T-T_{0}\right)
$$

where the sign of $\delta$ ' depends on the choice of $\mathrm{T}_{0}$. Frost states that their expression has no physical significance; it simply gives a reasonable fit to the data. The same is true for Eqs. (9) and (10). More work on a theoretical expression is needed.

Researchers should try to measure the half-width and line shift and the temperature dependence of these parameters. It has been found that adjusting the potential surface in CRB calculations by fitting $\gamma, \delta$, and $n$ simultaneously places strong constraints on the parameters describing the surface. What has been found is that only a unique set of parameters can reproduce all three line shape parameters [115-117]. It would be interesting to see how the addition of the temperature dependence of the line shift will affect the fits.

For new measurements to be useful more effort must be made to determine the true uncertainty of the measurements. An excellent discussion of the determination of uncertainties in line shape measurements can be found Ref. [142]. The emphasis should be on the accuracy of the measurement rather than the number of transitions measured.

\section{Acknowledgements}


The authors are pleased to acknowledge support of this research by the National Science Foundation through Grant No. AGS-1156862. Any opinions, findings, and conclusions or recommendations expressed in this material are those of the author(s) and do not necessarily reflect the views of the National Science Foundation. 


\section{Tables}

Table 1. Summary of measurement data for the $\mathrm{CO}_{2}-\mathrm{N}_{2}$ collision system.

Table 2 Summary of measurement data for the $\mathrm{CO}_{2}-\mathrm{O}_{2}$ collision system.

Table 3 Summary of measurement data for the $\mathrm{CO}_{2}$-air collision system.

Table 4 Summary of measurement data for the $\mathrm{CO}_{2}-\mathrm{CO}_{2}$ collision system.

Table 5 Database Index and corresponding line shape model.

Table 6 Intercomparison of the half-width and line shift data. See text for details.

Table 7 Isotopologue scaling factors for the half-width and line shift. 
Figures

Figure 1 Measured half-widths $\left(\mathrm{cm}^{-1} \mathrm{~atm}^{-1}\right)$ for nitrogen-broadening of the R16 transition of the $30012 \leftarrow 00001$ band of $\mathrm{CO}_{2}$ with reported uncertainties. Solid line is the average half-width, dashed and dash-dot lines are 1 and 2 standard deviations. See text for symbols and colors.

Figure 2 Measured line shifts $\left(\mathrm{cm}^{-1} \mathrm{~atm}^{-1}\right)$ for nitrogen-broadening of the R46 transition of the $30013 \leftarrow 00001$ band of $\mathrm{CO}_{2}$ with reported uncertainties. Solid line is the average half-width, dashed and dash-dot lines are 1 and 2 standard deviations. See text for symbols and colors.

Figure 3 Measured half-widths $\left(\mathrm{cm}^{-1} \mathrm{~atm}^{-1}\right)$ for self-broadening of the P20 transition of the $00011 \leftarrow 10001$ band of $\mathrm{CO}_{2}$ with reported uncertainties. Solid line is the average half-width, dashed and dash-dot lines are 1 and 2 standard deviations. See text for symbols and colors.

Figure 4 Measured line shifts $\left(\mathrm{cm}^{-1} \mathrm{~atm}^{-1}\right)$ for self-broadening of the R20 transition of the $30012 \leftarrow 00001$ band of $\mathrm{CO}_{2}$ with reported uncertainties. Solid line is the average half-width, dashed and dash-dot lines are 1 and 2 standard deviations. See text for symbols and colors.

Figure 5 Structure of the measured half-widths $\left(\mathrm{cm}^{-1} \mathrm{~atm}^{-1}\right.$, top panel), line shifts $\left(\mathrm{cm}^{-1} \mathrm{~atm}^{-1}\right.$, middle panel), and temperature dependence of the half-width (bottom panel) as a function of $m$ for the $30012 \leftarrow 00001$ band for $\mathrm{CO}_{2-}$ $\mathrm{CO}_{2}$. Colors and symbols refer to references given in the upper left of the top panel. 
Figure 6 Measured half-widths $\left(\mathrm{cm}^{-1} \mathrm{~atm}^{-1}\right.$, top panel) and line shifts $\left(\mathrm{cm}^{-1} \mathrm{~atm}^{-1}\right.$, bottom panel) with error estimates for air-broadening of the P18 line for a number of vibrational bands versus the Quantum Coordinate. The solid black line is the theoretical prediction from Ref. [124].

Figure 7 Measured half-widths $\left(\mathrm{cm}^{-1} \mathrm{~atm}^{-1}\right.$, top panel) and line shifts $\left(\mathrm{cm}^{-1} \mathrm{~atm}^{-1}\right.$, bottom panel) with error estimates for self-broadening of the R20 line for a number of vibrational bands versus the Quantum Coordinate. The solid black line is the theoretical prediction from Ref. [124].

Figure 8 Measured half-widths $\left(\mathrm{cm}^{-1} \mathrm{~atm}^{-1}\right)$ for self-broadening of the R12 transition of the $30013 \leftarrow 00001$ band of $\mathrm{CO}_{2}$ with reported uncertainties. Points 1, 2, 5-7 use the Voigt model, point 3 the Rautian model, point 4 the speed-dependent model of Ref. [27], and point 8 the speed-dependent model of Ref. [55]. Solid line is the average half-width, dashed and dashdot lines are 1 and 2 standard deviations. See text for symbols and colors.

Figure 9 Measured air-broadened half-widths $\left(\mathrm{cm}^{-1} \mathrm{~atm}^{-1}\right)$ for the P34 transition demonstrating the isotopologue effect. Measurements for ${ }^{12} \mathrm{C}^{16} \mathrm{O}_{2}$ in blue and those for ${ }^{13} \mathrm{C}^{16} \mathrm{O}_{2}$ in red. Top and bottom panels are for the $00011 \leftarrow 10001$ and $00011 \leftarrow 10002$ bands respectively.

Figure 10 Measured air-broadened temperature exponents for different line shape models (see table 5 for description) versus the Quantum Coordinate.

Figure 11 Measured temperature dependence of the self-broadened half-width for $\mathrm{CO}_{2}$ transitions. In black are the recent measurements of Predoi-Cross et 
al. [68] for the $30012 \leftarrow 00001$ and $30013 \leftarrow 00001$ bands. The plot symbols reflect the line shape model used to reduce the data. 
Table 1 Summary of measurement data for the $\mathrm{CO}_{2}-\mathrm{N}_{2}$ collision system.

\begin{tabular}{|c|c|c|c|c|c|c|c|c|c|c|}
\hline $\begin{array}{r}\mathrm{CO}_{2}-\mathrm{N}_{2} \\
\text { Band }\end{array}$ & $\mathrm{J}_{\max }$ & $\mathrm{n}_{t}$ & $\mathrm{n}_{\delta}$ & $\mathrm{n}_{n}$ & $\gamma_{\min }{ }^{*}$ & $\gamma_{\max }{ }^{*}$ & $\delta_{\min }{ }^{*}$ & $\delta_{\max }{ }^{*}$ & $n_{\min }$ & $n_{\max }$ \\
\hline $00011 \leftarrow 00001$ & 82 & 268 & 133 & 21 & 58.50 & 96.96 & -3.72 & -0.09 & 0.720 & 0.860 \\
\hline $00011 \leftarrow 10001$ & 48 & 266 & 210 & & 60.79 & 97.00 & -4.32 & 0.90 & & \\
\hline $00031 \leftarrow 00001$ & 36 & 23 & 26 & & 71.10 & 96.30 & -9.50 & -5.00 & & \\
\hline $11101 \leftarrow 00001$ & 60 & 37 & & & 74.18 & 106.48 & & & & \\
\hline $11101 \leftarrow 10002$ & 38 & 19 & & & 66.51 & 83.75 & & & & \\
\hline $20012 \leftarrow 00001$ & 46 & 17 & 13 & 2 & 61.10 & 111.97 & -7.00 & -3.40 & 1.059 & 1.130 \\
\hline $30012 \leftarrow 00001$ & 50 & 102 & 51 & & 55.73 & 97.29 & -8.49 & -2.73 & & \\
\hline $30013 \leftarrow 00001$ & 50 & 106 & 49 & 2 & 60.71 & 99.49 & -8.52 & -3.53 & 0.740 & 0.800 \\
\hline $00011 \leftarrow 10002$ & 52 & 227 & 218 & & 67.11 & 98.40 & -4.90 & 1.73 & & \\
\hline $01111 \leftarrow 01101$ & 52 & 63 & & 7 & 69.03 & 95.00 & & & 0.860 & 0.860 \\
\hline $10001 \leftarrow 00001$ & 50 & 93 & 92 & & 63.50 & 105.10 & -5.50 & 4.30 & & \\
\hline $10001 \leftarrow 01101$ & 40 & 9 & & & 62.45 & 83.36 & & & & \\
\hline $01101 \leftarrow 00001$ & 56 & 27 & & 16 & 59.55 & 91.32 & & & 0.608 & 1.132 \\
\hline $10002 \leftarrow 00001$ & 46 & 93 & 90 & & 62.10 & 99.60 & -5.60 & 1.40 & & \\
\hline $10011 \leftarrow 00001$ & 48 & 9 & & & 68.70 & 95.80 & & & & \\
\hline $20031 \leftarrow 00001$ & 20 & 1 & & & 70.00 & 70.00 & & & & \\
\hline $02211 \leftarrow 02201$ & 36 & 3 & & 3 & 65.63 & 84.55 & & & 0.860 & 0.860 \\
\hline
\end{tabular}

in units of $\mathrm{cm}^{-1} \mathrm{~atm}^{-1}$ 
Table 2 Summary of measurement data for the $\mathrm{CO}_{2}-\mathrm{O}_{2}$ collision system.

\begin{tabular}{|l|llllllllll|}
\hline $\mathrm{CO}_{2}-\mathrm{O}_{2}$ & & & & & & & & & \\
Band & $\mathrm{J}_{\max }$ & $\mathrm{n}_{r}$ & $\mathrm{n}_{\circ}$ & $\mathrm{n}_{n}$ & $\gamma_{\min }{ }^{*}$ & $\gamma_{\max }{ }^{*}$ & $\delta_{\min }{ }^{*}$ & $\delta_{\max }{ }^{*}$ & $n_{\min }$ & $n_{\max }$ \\
\hline $00011 \leftarrow 00001$ & 82 & 21 & & 9 & 51.30 & 83.80 & & & 0.820 & 0.820 \\
$11101 \leftarrow 00001$ & 60 & 31 & & & 64.16 & 93.79 & & & & \\
$11101 \leftarrow 10002$ & 26 & 18 & & & 56.34 & 73.98 & & & & \\
$20012 \leftarrow 00001$ & 46 & 13 & 13 & & 54.70 & 73.00 & -7.10 & -2.90 & & \\
$30012 \leftarrow 00001$ & 56 & 72 & 61 & & 53.13 & 86.99 & -14.44 & -2.98 & & \\
$30013 \leftarrow 00001$ & 56 & 76 & 56 & 2 & 53.20 & 86.43 & -16.36 & -1.24 & 0.660 & 0.720 \\
$00011 \leftarrow 10002$ & 30 & & & 4 & & & & & 0.930 & 1.090 \\
$10011 \leftarrow 00001$ & 48 & 9 & & & 57.50 & 85.10 & & & & \\
\hline
\end{tabular}

in units of $\mathrm{cm}^{-1} \mathrm{~atm}^{-1}$ 
Table 3 Summary of measurement data for the $\mathrm{CO}_{2}$-air collision system.

\begin{tabular}{|l|llllllllll|}
\hline $\mathrm{CO}_{2}$-air & & & & & & & & \\
Band & $\mathrm{J}_{\max }$ & $\mathrm{n}_{r}$ & $\mathrm{n}_{s}$ & $\mathrm{n}_{n}$ & $\gamma_{\min }{ }^{*}$ & $\gamma_{\max }{ }^{*}$ & $\delta_{\min }{ }^{*}$ & $\delta_{\max }{ }^{*}$ & $n_{\min }$ & $n_{\max }$ \\
\hline $00011 \leftarrow 00001$ & 82 & 71 & 63 & & 57.00 & 92.80 & -6.40 & -1.10 & & \\
$00011 \leftarrow 10001$ & 48 & 226 & 218 & 62.80 & 98.33 & -4.69 & 0.70 & & \\
$00031 \leftarrow 00001$ & 48 & 30 & 41 & 66.40 & 94.50 & -12.10 & -3.86 & & \\
$20012 \leftarrow 00001$ & 64 & 60 & 53 & & 60.91 & 95.20 & -7.60 & -2.08 & & \\
$20013 \leftarrow 00001$ & 62 & 58 & 61 & & 63.20 & 94.40 & -7.41 & -2.32 & & \\
$30012 \leftarrow 00001$ & 56 & 290 & 263 & 55 & 49.05 & 95.75 & -15.21 & -0.62 & 0.646 & 0.884 \\
$30013 \leftarrow 00001$ & 56 & 284 & 260 & 56 & 63.14 & 96.42 & -12.16 & -2.40 & 0.673 & 0.876 \\
$00011 \leftarrow 10002$ & 52 & 226 & 220 & & 62.40 & 93.21 & -4.20 & 1.83 & & \\
$10001 \leftarrow 00001$ & 50 & 93 & 93 & & 63.10 & 92.60 & -3.10 & 1.70 & & \\
$31113 \leftarrow 01101$ & 31 & 49 & 39 & & 67.25 & 89.47 & -10.28 & -0.02 & & \\
$20011 \leftarrow 00001$ & 60 & 51 & 50 & & 62.40 & 95.50 & -8.08 & -2.27 & & \\
$21112 \leftarrow 01101$ & 47 & 52 & 42 & & 66.20 & 94.20 & -6.36 & -2.61 & & \\
$21113 \leftarrow 01101$ & 45 & 37 & 60 & & 66.70 & 92.20 & -6.71 & -2.67 & & \\
$21111 \leftarrow 01101$ & 44 & 48 & 50 & & 67.30 & 90.90 & -6.05 & -2.81 & & \\
$10002 \leftarrow 00001$ & 46 & 93 & 91 & 64.40 & 106.40 & -3.50 & 1.30 & & \\
$10011 \leftarrow 00001$ & 50 & 6 & & & 66.70 & 77.50 & & & & \\
$20031 \leftarrow 00001$ & 20 & 1 & & & 80.00 & 80.00 & & & & \\
\hline
\end{tabular}

in units of $\mathrm{cm}^{-1} \mathrm{~atm}^{-1}$ 
Table 4 Summary of measurement data for the $\mathrm{CO}_{2}-\mathrm{CO}_{2}$ collision system.

\begin{tabular}{|c|c|c|c|c|c|c|c|c|c|c|}
\hline $\begin{array}{l}\mathrm{CO}_{2}-\mathrm{CO}_{2} \\
\text { Band }\end{array}$ & $\mathrm{J}_{\max }$ & $\mathbf{n}_{v}$ & $\mathrm{n}_{\delta}$ & $\mathrm{n}_{n}$ & $\gamma_{\min }{ }^{*}$ & $\gamma_{\max }{ }^{*}$ & $\delta_{\min }{ }^{*}$ & $\delta_{\max }^{*}$ & $n_{\min }$ & $n_{\max }$ \\
\hline $00011 \leftarrow 00001$ & 82 & 125 & & 25 & 53.19 & 126.46 & & & 0.891 & 2.158 \\
\hline $00011 \leftarrow 10001$ & 60 & 213 & 114 & 14 & 64.00 & 127.20 & -4.80 & -0.60 & 0.580 & 0.820 \\
\hline $00031 \leftarrow 00001$ & 56 & 69 & 28 & & 78.00 & 126.70 & -13.30 & -4.75 & & \\
\hline $01121 \leftarrow 00001$ & 38 & 47 & 25 & & 79.40 & 116.70 & -8.71 & -4.31 & & \\
\hline $10011 \leftarrow 10002$ & 32 & 34 & & & 82.50 & 113.50 & & & & \\
\hline $11101 \leftarrow 00001$ & 12 & 6 & & & 107.00 & 134.30 & & & & \\
\hline $11101 \leftarrow 10002$ & 40 & 20 & & & 75.81 & 104.64 & & & & \\
\hline $20012 \leftarrow 00001$ & 74 & 160 & 48 & 15 & 64.80 & 127.00 & -11.60 & -2.36 & 0.48 & 0.801 \\
\hline $20013 \leftarrow 00001$ & 72 & 161 & 66 & & 67.70 & 126.40 & -9.61 & -2.81 & & \\
\hline $21102 \leftarrow 01111$ & 59 & 8 & & & 57.80 & 74.00 & & & & \\
\hline $30012 \leftarrow 00001$ & 62 & 382 & 270 & 112 & 56.48 & 135.70 & -20.53 & -1.90 & 0.428 & 0.871 \\
\hline $31112 \leftarrow 01111$ & 16 & 1 & & & 103.94 & 103.94 & & & & \\
\hline $30013 \leftarrow 00001$ & 62 & 354 & 232 & 112 & 34.88 & 134.41 & -12.68 & -2.00 & 0.429 & 0.823 \\
\hline $00011 \leftarrow 10002$ & 62 & 159 & 122 & 19 & 63.60 & 126.70 & -3.40 & -0.70 & 0.600 & 1.090 \\
\hline $01111 \leftarrow 01101$ & 48 & 42 & & & 65.34 & 124.53 & & & & \\
\hline $10001 \leftarrow 00001$ & 50 & 23 & & 12 & 49.93 & 123.38 & & & 0.706 & 0.990 \\
\hline $10001 \leftarrow 01101$ & 40 & 9 & & & 99.32 & 120.69 & & & & \\
\hline $01101 \leftarrow 00001$ & 56 & 23 & & 10 & 73.40 & 123.05 & & & 0.187 & 0.743 \\
\hline $31112 \leftarrow 01101$ & 48 & 129 & 121 & & 69.91 & 147.34 & -11.55 & 0.30 & & \\
\hline $40013 \leftarrow 10002$ & 30 & 24 & 17 & & 86.91 & 116.91 & -14.24 & -2.90 & & \\
\hline $31113 \leftarrow 01101$ & 46 & 122 & 111 & & 76.77 & 125.09 & -9.89 & -0.72 & & \\
\hline $40014 \leftarrow 10002$ & 32 & 18 & 11 & & 70.77 & 141.94 & -14.07 & -2.63 & & \\
\hline $20011 \leftarrow 00001$ & 72 & 65 & 59 & & 66.30 & 127.10 & -11.77 & -2.55 & & \\
\hline $21112 \leftarrow 01101$ & 62 & 58 & 43 & & 68.90 & 111.60 & -9.48 & -4.13 & & \\
\hline $21113 \leftarrow 01101$ & 59 & 69 & 62 & & 66.80 & 123.30 & -9.27 & -2.64 & & \\
\hline $21111 \leftarrow 01101$ & 57 & 73 & 54 & & 69.50 & 121.70 & -8.80 & -2.54 & & \\
\hline $30014 \leftarrow 00001$ & 48 & 47 & 44 & & 72.60 & 120.60 & -10.77 & -2.82 & & \\
\hline $30011 \leftarrow 00001$ & 44 & 34 & 31 & & 76.00 & 112.30 & -9.80 & -2.76 & & \\
\hline $01131 \leftarrow 01101$ & 37 & 50 & & & 86.90 & 116.30 & & & & \\
\hline $10002 \leftarrow 00001$ & 32 & 7 & & & 85.80 & 109.90 & & & & \\
\hline $10011 \leftarrow 00001$ & 70 & 2 & & 2 & 130.00 & 171.00 & & & 0.654 & 0.695 \\
\hline $10012 \leftarrow 00001$ & 42 & 19 & & & 78.37 & 126.28 & & & & \\
\hline $12211 \leftarrow 00001$ & 46 & 19 & & & 157.87 & 223.97 & & & & \\
\hline $20031 \leftarrow 00001$ & 30 & 14 & & & 63.00 & 106.98 & & & & \\
\hline $11102 \leftarrow 01101$ & 48 & 20 & 20 & & 80.07 & 111.73 & -11.36 & -11.36 & & \\
\hline $02211 \leftarrow 02201$ & 15 & 1 & 1 & & 102.60 & 102.60 & -3.44 & -3.44 & & \\
\hline $12201 \leftarrow 01101$ & 46 & 105 & & & 75.40 & 126.50 & & & & \\
\hline
\end{tabular}

in units of $\mathrm{cm}^{-1} \mathrm{~atm}^{-1}$ 
Table 5 Database Index and corresponding line shape model.

\begin{tabular}{|c|c|c|c|c|c|c|}
\hline Index & Model & $\begin{array}{l}\text { Plot } \\
\text { symbol }\end{array}$ & $\mathrm{CO}_{2}-\mathrm{N}_{2}$ & $\mathrm{CO}_{2}-\mathrm{O}_{2}$ & $\mathrm{CO}_{2}$-air & $\mathrm{CO}_{2}-\mathrm{CO}_{2}$ \\
\hline 1 & Voigt & + & $X$ & $X$ & $\mathrm{X}$ & $X$ \\
\hline 2 & Galatry & * & $\mathrm{X}$ & $\mathrm{X}$ & $X$ & $\mathrm{X}$ \\
\hline 3 & $\begin{array}{l}\text { Speed dependent } \\
\text { Voigt }\end{array}$ & 0 & & & $\mathrm{X}$ & \\
\hline 4 & Rautian & $\times$ & & & $X$ & $X$ \\
\hline 5 & $\begin{array}{l}\text { Speed dependent } \\
\text { Nelkin-Ghatak }\end{array}$ & $\square$ & & & $\mathrm{X}$ & \\
\hline 6 & $\begin{array}{l}\text { Speed dependent } \\
\text { Rautian }\end{array}$ & $\Delta$ & & & & \\
\hline 7 & Lorentz (pure) & $\nabla$ & $\mathrm{X}$ & $\mathrm{X}$ & & $\mathrm{X}$ \\
\hline 8 & $\begin{array}{l}\text { Speed dependent } \\
\text { Lorentz }\end{array}$ & is & & & & $\mathrm{X}$ \\
\hline 9 & $\begin{array}{l}\text { Modified Voigt } \\
\text { (includes line- } \\
\text { mixing) }\end{array}$ & $\boldsymbol{\Delta}$ & $\mathrm{X}$ & & & $\mathrm{X}$ \\
\hline 10 & $\begin{array}{l}\text { Speed dependent - } \\
\text { See Ref. [27] }\end{array}$ & $\mathbf{\square}$ & $\mathrm{X}$ & $\mathrm{X}$ & $\mathrm{X}$ & $\mathrm{X}$ \\
\hline 11 & $\begin{array}{l}\text { Speed dependent - } \\
\text { See Ref. [55] }\end{array}$ & O & & & $\mathrm{X}$ & $\mathrm{X}$ \\
\hline
\end{tabular}


Table 6 Intercomparison of the half-width and line shift data. See text for details.

\begin{tabular}{|c|c|c|c|c|c|}
\hline $\mathrm{CO}_{2}-\mathrm{N}_{2}$ & \multicolumn{3}{|c|}{$\gamma$} & \multicolumn{2}{|r|}{$\delta$} \\
\hline$n_{i}$ & $n$ data & APD & AAPD & $n$ data & AR \\
\hline 2 & 68 & 2.79 & 5.52 & 15 & 1.17 \\
\hline 3 & 38 & 0.46 & 5.42 & 51 & 1.25 \\
\hline 4 & 16 & 0.82 & 4.25 & & \\
\hline 5 & 68 & 0.38 & 1.78 & 73 & 1.22 \\
\hline 6 & 40 & 0.68 & 2.34 & & \\
\hline 7 & 2 & 2.52 & 5.84 & & \\
\hline 8 & 1 & 1.54 & 2.40 & & \\
\hline $\mathrm{CO}_{2}-\mathrm{O}_{2}$ & & $\gamma$ & & & $\delta$ \\
\hline 2 & 36 & 0.23 & 5.15 & 5 & 0.65 \\
\hline 3 & 3 & 1.70 & 2.07 & & \\
\hline $\mathrm{CO}_{2}$-air & & $\gamma$ & & & $\delta$ \\
\hline 2 & 21 & -1.80 & 2.74 & 15 & 1.02 \\
\hline 3 & 15 & -1.53 & 1.98 & 14 & 2.27 \\
\hline 4 & 22 & 0.30 & 1.67 & 21 & 1.03 \\
\hline 5 & 134 & -0.17 & 1.06 & 159 & 1.18 \\
\hline 6 & 18 & -0.56 & 2.82 & 4 & 1.24 \\
\hline 7 & 10 & -2.38 & 2.92 & & \\
\hline 8 & 2 & 2.91 & 5.84 & & \\
\hline 9 & 2 & 1.81 & 5.69 & & \\
\hline $\mathrm{CO}_{2}-\mathrm{CO}_{2}$ & & $\gamma$ & & & $\delta$ \\
\hline 2 & 234 & 0.28 & 2.97 & 216 & 0.96 \\
\hline 3 & 150 & -1.67 & 4.00 & 4 & 0.99 \\
\hline 4 & 21 & -0.28 & 3.38 & 74 & 0.99 \\
\hline 5 & 27 & -1.62 & 4.25 & 29 & 1.03 \\
\hline 6 & 55 & -0.20 & 6.01 & 5 & 1.54 \\
\hline 7 & 18 & 1.12 & 3.73 & & \\
\hline 8 & 29 & 2.65 & 5.03 & & \\
\hline
\end{tabular}


Table 7 Isotopologue scaling factors for the half-width and line shift.

\begin{tabular}{|c|l|l|l|}
\hline Broadening species & ${ }^{13} \mathrm{C}^{16} \mathrm{O}_{2} /{ }^{12} \mathrm{C}^{16} \mathrm{O}_{2}$ & ${ }^{16} \mathrm{O}^{12} \mathrm{C}^{18} \mathrm{O} /{ }^{12} \mathrm{C}^{16} \mathrm{O}_{2}$ & ${ }^{16} \mathrm{O}^{13} \mathrm{C}^{18} \mathrm{O} /{ }^{12} \mathrm{C}^{16} \mathrm{O}_{2}$ \\
\hline $\mathrm{N}_{2}$ & 0.9978 & 0.9957 & 0.9937 \\
\hline $\mathrm{O}_{2}$ & 0.9976 & 0.9954 & 0.9932 \\
\hline air & 0.9978 & 0.9956 & 0.9936 \\
\hline $\mathrm{CO}_{2}$ & 0.9972 & 0.9945 & 0.9919 \\
\hline
\end{tabular}




\section{REFERENCES}

[1] Tans P, Keeling R, Trends in Carbon Dioxide: Recent Monthly $\mathrm{CO}_{2}$ at Mauna Loa, 2012, Available from: http://www.esrl.noaa.gov/gmd/ccgg/trends.

[2] Rothman LS, Gordon IE, Barbe A, Benner DC, Bernath PF, Birk M, Boudon V, Brown LR, Campargue A, Champion J-P, Chance K, Coudert LH, Dana V, Devi VM, Fally S, Flaud J-M, Gamache RR, Goldman A, Jacquemart D, Kleiner I, Lacome N, Lafferty WJ, Mandin J-Y, Massie ST, Mikhailenko SN, Miller CE, Moazzen-Ahmadi N, Naumenko OV, Nikitin AV, Orphal J, Perevalov VI, Perrin A, Predoi-Cross A, Rinsland CP, Rotger M, Simeckova M, Smith MAH, Sung K, Tashkun SA, Tennyson J, Toth RA, Vandaele AC, Auwera JV. The HITRAN 2008 molecular spectroscopic database, J. Quant. Spectrosc. Radiat. Transfer 2009; 110: 533-72, doi 10.1016/j.jqsrt.2009.02.013.

[3] Keeling CD, Variations in concentration and isotopic abundances of atmospheric carbon dioxide, Proceedings of the conference on recent research in climatology, Committee on Research in Water Resources and University of California, Scripps Institution of Oceanography, La Jolla, California, 1957.

[4] Keeling CD. The Concentration and Isotopic Abundances of Carbon Dioxide in the Atmosphere, Tellus 1960; 12: 200-3.

[5] Lorius C, Jouzel J, Ritz C, Merlivat L, Barkov NI, Korotkevich YS, Kotlyakov VM. A 150,000-year climate record from Antartic ice, Nature 1985; 316: 591-6.

[6] Petit JR, Jouzel J, Raynaud D, Barkov NI, Barnola J-M, Basile I, Bender M, Chappellaz J, Davisk M, Delaygue G, Delmotte M, Kotlyakov VM, Legrand M, Lipenkov VY, Lorius C, Pépin L, Ritz C, Saltzman E, Stievenard M. Climate and atmospheric history of the past 420,000 years from the Vostok ice core, Antarctica, Nature 1999; 399: 429-36.

[7] IPCC. Climate Change 2007: The Physical Science Basis. Contribution of Working Group I to the Fourth Assessment Report of the Intergovernmental Panel on Climate Change, 2007.

[8] Toon GC, Blavier J-FL, Washenfelder RA, Wunch D, Keppel-Aleks G, Wennberg PO, Connor BJ, Sherlock V, Griffith DWT, Deutscher NM, Notholt J, Total Column Carbon Observing Network (TCCON), Fourier Transform Spectroscopy, Vancouver, Canada, 2009.

[9] Toon GC. The JPL MkIV interferometer, Opt. Photon, News 1991; 2: 19- 21.

[10] Toon GC, Blavier J-F, Sen B, Margitan JJ, Webster CR, May RD, Fahey D, Gao R, Negro LD, Proffitt M, Elkins J, Romashkin PA, Hurst DF, Oltmans S, Atlas E, Schauffler S, Flocke F, Bui TP, Stimpfle RM, Bonne GP, Voss PB, Cohen RC. Comparison of MkIV balloon and ER-2 aircraft measurements of atmospheric trace gases, J. Geophys. Res 1999; 104: 26,779-26,90.

[11] Parkinson CL. Aqua: An Earth-Observing Satellite Mission to Examine Water and Other Climate Variables, IEEE Trans. Geosci. Remote Sens. 2003; 41: 17383, doi 10.1109/TGRS.2002.808319.

[12] Aumann HH, Gregorich D, Gaiser S. AIRS hyper-spectral measurements for climate research: Carbon dioxide and nitrous oxide effects, Geophys. Res. Lett. 2005; 32: L05806, doi 0.1029/2004GL021784. 
[13] Kramer HJ. Observation of the Earth and its Environment - Survey of Missions and Sensors, Springer Verlag, 2002.

[14] Chalon G, Cayla F, Diebel D, IASI : An Advance Sounder for Operational Meteorology, Proceedings of the 52nd Congress of IAF, Toulouse, France, 1-5 Oct., 2001.

[15] Inoue G, Yokota T, Oguma H, Higurashi A, Morino I, T. Aoki, Overview of Greenhouse Gases Observing Satellite (GOSAT) of Japan, AGU 2004 Fall Meeting, San Francisco, California, USA, 13-17 December, 2004.

[16] Crisp D, Atlas RM, Breon F-M, Brown LR, Burrows JP, Ciais P, Connor BJ, Doney SC, Fung IY, Jacob DJ, Miller CE, O'Brien D, Pawson S, Randerson JT, Rayner P, Salawitch RJ, Sander SP, Sen B, Stephens GL, Tans PP, Toon GC, Wennberg PO, Wofsy SC, Yung YL, Kuang Z, Chudasama B, Sprague G, Weiss B, Pollock R, Kenyon D, Schroll S. The Orbiting Carbon Observatory (OCO) Mission, Adv. Space Res. 2004; 34: 700-9, doi 10.1016/j.asr.2003.08.062.

[17] Crisp D, Miller C, The Need for Atmospheric Carbon Dioxide Measurements from Space: Contributions from a Rapid Reflight of the Orbiting Carbon Observatory. http://www.nasa.gov/pdf/363474main_OCO_Reflight.pdf. 2009, Jet Propulsion Laboratory: Pasadena.

[18] Miller CE, Brown LR, Toth RA, Benner DC, Devi VM. Spectroscopic challenges for high accuracy retrievals of atmospheric $\mathrm{CO} 2$ and the Orbiting Carbon Observatory (OCO) experiment, C. R. Physique 2005; 6: 876-87.

[19] Pumphrey HC, Buehler S. Instrumental and Spectral Parameters :their effect on and measurement by microwave limb sounding of the atmosphere, J. Quant. Spectrosc. Radiat. Transfer 2000; 64: 421-37.

[20] Bosenberg J. Measurements of the pressure shift of water vapor absorption lines by simultaneous photoacoustic spectroscopy, Appl. Opt. 1985; 24: 3531-4.

[21] Devi VM, Chris Benner D, Smith MAH, Brown LR, Dulick M. Absolute intensity measurements of the ${ }^{12} \mathrm{C}^{16} \mathrm{O}_{2}$ laser bands near $10 \mu \mathrm{m}$, Journal of Quantitative Spectroscopy and Radiative Transfer 2003; 76: 393-410, doi http://dx.doi.org/10.1016/S0022-4073(02)00067-5.

[22] Devi VM, Benner DC, Smith MAH, Brown LR, Dulick M. Multispectrum analysis of pressure broadening and pressure shift coefficients in the ${ }^{12} \mathrm{C}^{16} \mathrm{O}_{2}$ and ${ }^{13} \mathrm{C}^{16} \mathrm{O}_{2}$ laser bands J. Quant. Spectrosc. Radiat. Transfer 2003; 76: 411-34.

[23] Chu WP, Chiou EW, Larsen JC, Thomason LW, Rind D, Buglia JJ, Oltmans S, McCormick MP, McMaster LM. Algorithms and Sensitivity Analyses for Stratospheric Aerosol and Gas Experiment II Water Vapor Retrieval, J. Geophys. Res. 1993; 98: 4857-66.

[24] Payne VH, Delamere JS, Cady-Pereira KE, Gamache RR, Moncet J-L, Mlawer E, Clough SA. Air-broadened half-widths of the $22 \mathrm{GHz}$ and $183 \mathrm{GHz}$ water vapor lines, IEEE Transactions in Geoscience and Remote Sensing 2007; 46: 3601-17.

[25] Delamere JS, Clough SA, Payne VH, Mlawer EJ, Turner DD, Gamache RR. A Far-Infrared Radiative Closure Study in the Arctic: Application to Water Vapor, J. Geophys. Res. 2010; 115: D17106, doi 10.1029/2009JD012968.

[26] Liljegren JC, Boukabara S-A, Cady-Pereira K, Clough SA. The effect of the halfwidth of the 22-GHz water vapor line on retrievals of temperature and water 
vapor profiles with a 12-channel microwave radiometer, IEEE Trans. Geosci. Remote Sensing 2005; 43: 1102-8.

[27] Devi VM, Benner DC, Miller CE, Predoi-Cross A. Lorentz half-width, pressureinduced shift and speed-dependent coefficients in oxygen-broadened $\mathrm{CO}_{2}$ bands at 6227 and $6348 \mathrm{~cm}^{-1}$ using a constrained multispectrum analysis, J. Quant. Spectrosc. Radiat. Transfer 2010; 111: 2355-69, doi 10.1016/j.jqsrt.2010.06.003.

[28] Tanaka T, Fukabori M, Sugita T, Nakajima H, Yokota T, Watanabe T, Sasano Y. Spectral line parameters for $\mathrm{CO}_{2}$ bands in the 4.8- to 5.3- $\mu \mathrm{m}$ region, J. Mol. Spectrosc. 2006; 239: 1-10, doi 10.1016/j.jms.2006.05.013.

[29] Valero FPJ, Suárez CB. Measurement at different temperatures of absolute intensities, line half-widths, and broadening by Ar and $N_{2}$ for the $30^{0} 1_{\mathrm{II}} \leftarrow 00^{0} 0$ band of $\mathrm{CO}_{2}$, J. Quant. Spectrosc. Radiat. Transfer 1978; 19: 579-90.

[30] Suárez CB, Valero FPJ. Intensities, self-broadening, and broadening by Ar and $\mathrm{N}_{2}$ for the $301_{\mathrm{III}} \leftarrow 000$ band of $\mathrm{CO}_{2}$ measured at different temperatures, J. Mol. Spectrosc. 1978; 71: 46-63,.

[31] Pouchet I, Zéninari V, Parvitte B, Durry G. Diode laser spectroscopy of $\mathrm{CO}_{2}$ in the $1.6 \mu \mathrm{m}$ region for the in situ sensing of the middle atmosphere, J. Quant. Spectrosc. Radiat. Transfer 2004; 83: 619-28.

[32] De Rosa M, Corsi C, Gabrysch M, D’Amato F. Collisional broadening and shift of lines in the $2 v_{1}+2 v_{2}+v_{3}$ band of $\mathrm{CO}_{2}$, J. Quant. Spectrosc. Radiat. Transfer 1999; 61: 97-104.

[33] Nakamichi S, Kawaguchi Y, Fukuda H, Enami S, Hashimoto S, Kawasaki M, Umekawa T, Morino I, Suto H, Inoue G. Buffer-gas pressure broadening for the $\left(\begin{array}{lll}3 & 0^{0} & 1\end{array}\right)_{\mathrm{III}} \leftarrow\left(\begin{array}{lll}0 & 0 & 0\end{array}\right)$ band of $\mathrm{CO}_{2}$ measured with continuous-wave cavity ring-down spectroscopy, Phys. Chem. Chem. Phys. 2006; 8: 364-8.

[34] Hikida T, Yamada KMT. $\mathrm{N}_{2}$ - and $\mathrm{O}_{2}$-broadening of $\mathrm{CO}_{2}$ for the $\left(30^{0} 1\right)_{\mathrm{III}} \leftarrow\left(00^{0} 0\right)$ band at $6231 \mathrm{~cm}^{-1}$, J. Mol. Spectrosc. 2006; 239: 154-9.

[35] Rosenmann L, Hartmann J-M, Perrin MY, Taine J. Collisional broadening of $\mathrm{CO}_{2}$ IR lines. II. Calculations, J. Chem. Phys. 1988; 88: 2999-3006.

[36] Devi VM, Benner DC, Smith MAH, Rinsland CP. Air- and $\mathrm{N}_{2}$-Broadening Coefficients and Pressure-Shift Coefficients in the ${ }^{12} \mathrm{C}^{16} \mathrm{O}_{2}$ Laser Bands, J. Quant. Spectrosc. Radiat. Transfer 1998; 59: 137-49.

[37] Devi VM, Benner DC, Rinsland CP, Smith MAH. Measurements of Pressure Broadening and Pressure Shifting by Nitrogen in the $4.3 \mu \mathrm{m}$ Band of ${ }^{12} \mathrm{C}^{16} \mathrm{O}_{2}$, J. Quant. Spectrosc. Radiat. Transfer 1992; 48: 581-9.

[38] Johns JWC. Absolute Intensity and Pressure Broadening Measurements of $\mathrm{CO}_{2}$ in the 4.3- $\mu \mathrm{m}$ Region, J. Mol. Spectrosc. 1987; 125: 442-64.

[39] Li JS, Liu K, Zhang WJ, Chen WD, Gao XM. Self-, $\mathrm{N}_{2}$ - and $\mathrm{O}_{2}$-broadening coefficients for the ${ }^{12} \mathrm{C}^{16} \mathrm{O}_{2}$ transitions near-IR measured by a diode laser photoacoustic spectrometer, J. Mol. Spectrosc. 2008; 252: 9-16.

[40] Corsi C, D'Amato F, De Rosa M, Modugno G. High-resolution measurements of line intensity, broadening and shift of $\mathrm{CO}_{2}$ around $2 \mu \mathrm{m}$, Eur. Phys. J. D 1999; 6: 327-32.

[41] Dana V, Valentin A, Hamdouni A, Rothman LS. Line intensities and broadening parameters of the $11101 \leftarrow 10002$ band of ${ }^{12} \mathrm{C}^{16} \mathrm{O}_{2}$, Appl. Opt. 1989; 28: 2562-6. 
[42] Devi VM, Benner DC, Smith MAH, Rinsland CP. Nitrogen broadening and shift coefficients in the 4.2-4.5 $\mu \mathrm{m}$ bands of $\mathrm{CO}_{2}$, J. Quant. Spectrosc. Radiat. Transfer 2003; 76: 289-307.

[43] Devi VM, Benner DC, Smith MAH, Rinsland CP. Pressure Broadening and Pressure Shift Coefficients in the $2 v_{2}{ }^{0}$ and $v_{1}$ Bands of ${ }^{16} \mathrm{O}^{13} \mathrm{C}^{18} \mathrm{O}$, J. Quant. Spectrosc. Radiat. Transfer 1998; 60: 771-83.

[44] Thibault F, Boissoles J, Le Doueen R, Bouanich JP, Areas P, Boulet C. Pressure induced shifts of $\mathrm{CO}_{2}$ lines: Measurements in the $00^{0} 3-00^{0} 0$ band and theoretical analysis, J. Chem. Phys. 1992; 96: 4945-53, doi 10.1063/1.462737.

[45] Margottin-Maclou M, Dahoo P, Henry A, Valentin A, Henry L. Self-, $\mathrm{N}_{2-}$, and $\mathrm{O}_{2}$-broadening parameters in the $v_{3}$ and $v_{1}+v_{3}$ bands of ${ }^{12} \mathrm{C}^{16} \mathrm{O}_{2}$, J. Mol. Spectrosc. 1988; 131: 21-35,.

[46] Alwahabi ZT, Zetterberg J, Li ZS, Aldén M. High resolution polarization spectroscopy and laser induced fluorescence of $\mathrm{CO}_{2}$ around $2 \mu \mathrm{m}$, Eur. Phys. J. D 2007; 42: 41-7, doi 10.1140/epjd/e2006-00275-y.

[47] Boulet C, Arie E, Bouanich JP, Lacome N. Spectroscopie par Source Laser II, Etude Experimentale de l'Elargissement des Raies de la Transition 00 $0^{\circ} 1-\left(10^{\circ} 0\right.$, $02^{\circ} 0$ )। de $\mathrm{CO}_{2}$ Perturbe par $\mathrm{N}_{2}$. Application de la Theorie d' Anderson, Tsao et Curnutte au Calcul des Largeurs des Raies de $\mathrm{CO}_{2}$ Pur, et Perturbe par $\mathrm{N}_{2}$, Can J. Phys. 1972; 50: 2178-85.

[48] Bulanin MO, Bulychev VP, Khodos EB. Determination of the parameters of the vibrational-rotational lines in the 9.4 and $10.4 \mu \mathrm{m}$ bands of $\mathrm{CO}_{2}$ at different temperatures, Opt. Spectrosc. 1980; 48: 723-37.

[49] Eng RS, Mantz AW. Tunable Diode Laser Spectroscopy of $\mathrm{CO}_{2}$ in the 10- to 15$\mu \mathrm{m}$ Spectral Region- Lineshape and Q-Branch Head Absorption Profile, J. Mol. Spectrosc. 1979; 74: 33 1-344.

[50] Sirota JM, Reuter DC, Mumma MJ. Intensities and Broadening Coefficients for the Q Branch of the $4 \mathrm{v}_{2} \leftarrow \mathrm{v}_{1}+\mathrm{v}_{2}\left(471.511 \mathrm{~cm}^{-1}\right)$ Band of $\mathrm{CO}_{2}$, J. Quant. Spectrosc. Radiat. Transfer 1993; 50: 193-8.

[51] Gentry B, Strow LL. Line mixing in a $\mathrm{N}_{2}$-broadened $\mathrm{CO}_{2} Q$ branch observed with a tunable diode laser, J. Chem. Phys. 1987; 86: 5722-30.

[52] Toth RA, Miller CE, Devi VM, Benner DC, Brown LR. Air-broadened halfwidth and pressure shift coefficients of ${ }^{12} \mathrm{C}^{16} \mathrm{O}_{2}$ bands: $4750-7000 \mathrm{~cm}^{-1}$, J. Mol. Spectrosc. 2007; 246: 133-57, doi 10.1016/j.jms.2007.09.005.

[53] Devi VM, Benner DC, Brown LR, Miller CE, Toth RA. Line mixing and speed dependence in $\mathrm{CO}_{2}$ at $6348 \mathrm{~cm}^{-1}$ : Positions, intensities, and air- and selfbroadening derived with constrained multispectrum analysis, J. Mol. Spectrosc. 2007; 242: 90-117, doi 10.1016/j.jms.2007.02.018.

[54] Devi VM, Benner DC, Brown LR, Miller CE, Toth RA. Line mixing and speed dependence in $\mathrm{CO} 2$ at $6227.9 \mathrm{~cm}^{-1}$ : Constrained multispectrum analysis of intensities and line shapes in the $30013 \leftarrow 00001$ band, J. Mol. Spectrosc. 2007; 245: 52-80, doi 10.1016/j.jms.2007.05.015.

[55] Predoi-Cross A, McKellar ARW, Benner DC, Devi VM, Gamache RR, Miller CE, Toth RA, Brown LR. Temperature dependences for air-broadened Lorentz half-width and pressure shift coefficients in the $30013 \leftarrow 00001$ and $30012 \leftarrow$ 
00001 bands of $\mathrm{CO}_{2}$ near $1600 \mathrm{~nm}$, Can J. Phys. 2009; 87: 517-35, doi 10.1139/P08-137.

[56] Predoi-Cross A, Liu W, Holladay C, Unni AV, Schofield I, McKellar ARW, Hurtmans D. Line profile study of transitions in the $30012 \leftarrow 00001$ and $30013 \leftarrow$ 00001 bands of carbon dioxide perturbed by air, J. Mol. Spectrosc. 2007; 246: 98 - 112, doi 10.1016/j.jms.2007.08.008.

[57] Gulidova OS, E.Asfin R, Grigoriev IM, Filippov NN. Air pressure broadening and shifting of high-J lines of $(00011) \leftarrow(00001)$ band of ${ }^{12} \mathrm{C}^{16} \mathrm{O}_{2}$, J. Quant. Spectrosc. Radiat. Transfer 2010; 111: 2315 - 20, doi 10.1016/j.jqsrt.2010.04.027.

[58] Li JS, Liu K, Zhang WJ, Chen WD, Gao XM. Pressure-induced line broadening for the $(30012) \leftarrow(00001)$ band of $\mathrm{CO}_{2}$ measured with tunable diode laser photoacoustic spectroscopy, J. Quant. Spectrosc. Radiat. Transfer 2008; 109: 1575 - 85, doi 10.1016/j.jqsrt.2007.10.014.

[59] Li JS, Durry G, Cousin J, Joly L, Parvitte B, Flamant PH, Gibert F, Zéninari V. Tunable diode laser measurement of pressure-induced shift coefficients of $\mathrm{CO}_{2}$ around $2.05 \mu \mathrm{m}$ for Lidar application, J. Quant Spectrosc. Radiat. Transfer 2011; 112: 1411-9, doi 10.1016/j.jqsrt.2011.01.030.

[60] Farooq A, Jeffries JB, Hanson RK. High-pressure measurements of CO2 absorption near $2.7 \mu \mathrm{m}$ : Line mixing and finite duration collision effects, J. Quant Spectrosc. Radiat. Transfer 2010; 111: 949-60, doi 10.1016/j.jqsrt.2010.01.001.

[61] Joly L, Gibert F, Grouiez B, Grossel A, Parvitte B, Durry G, Zéninari V. A complete study of $\mathrm{CO}_{2}$ line parameters around $4845 \mathrm{~cm}^{-1}$ for Lidar applications, J. Quant. Spectrosc. Radiat. Transfer 2008; 109: 426-34, doi 10.1016/j.jqsrt.2007.06.003.

[62] Long DA, Bielska K, Lisak D, Havey DK, Okumura M, Miller CE, Hodges JT. The air-broadened, near-infrared $\mathrm{CO}_{2}$ line shape in the spectrally isolated regime: Evidence of simultaneous Dicke narrowing and speed dependence, J. Chem. Phys. 2011; 135: 064308, doi 10.1063/1.3624527.

[63] Henningsen J, Simonsen H. The (2201-0000) Band of $\mathrm{CO}_{2}$ at $6348 \mathrm{~cm}^{-1}$ : Linestrengths, Broadening Parameters, and Pressure Shifts, J. Molec. Spectrosc. 2000; 203: 16-27.

[64] Toth RA, Brown LR, Miller CE, Malathy Devi V, Benner DC. Self-broadened widths and shifts of ${ }^{12} \mathrm{C}^{16} \mathrm{O}_{2}: 4750-7000 \mathrm{~cm}^{-1}$, J. Molec. Spectrosc. 2006; 239: 243-71.

[65] Régalia-Jarlot L, Zéninari V, Parvitte B, Grossel A, Thomas X, von der Heyden P, Durry G. A complete study of the line intensities of four bands of $\mathrm{CO}_{2}$ around 1.6 and $2.0 \mu \mathrm{m}$ : A comparison between Fourier transform and diode laser measurements, J. Quant Spectrosc. Radiat. Transfer 2006; 101: 325-38.

[66] Hikida T, Yamada KMT, Fukabori M, Aoki T, Watanabe T. Intensities and selfbroadening coefficients of the $\mathrm{CO}_{2}$ Ro-vibrational transitions measured by a nearIR diode laser spectrometer, J. Mol. Spectrosc. 2005; 232: 202-12.

[67] Predoi-Cross A, Unni AV, Liu W, Schofield I, Holladay C, McKellar ARW, Hurtmans D. Line shape parameters measurement and computations for selfbroadened carbon dioxide transitions in the $30012 \leftarrow 00001$ and $30013 \leftarrow 00001$ 
bands, line mixing, and speed dependence, J. Mol. Spectrosc. 2007; 245: 34-51, doi 10.1016/j.jms.2007.07.004.

[68] Predoi-Cross A, Liu W, Murphy R, Povey C, Gamache RR, Laraia AL, McKellar ARW, Hurtmans DR, Malathy Devi V. Measurement and computations for temperature dependences of self-broadened carbon dioxide transitions in the $30012 \leftarrow 00001$ and $30013 \leftarrow 00001$ bands, J. Quant. Spectrosc. Radiat. Transfer 2010; 111: 1065-79, doi 10.1016/j.jqsrt.2010.01.003.

[69] Le Barbu T, Zéninari V, Parvitte B, Courtois D, Durry G. Line strengths and selfbroadening coefficients of carbon dioxide isotopologues $\left({ }^{13} \mathrm{CO}_{2}\right.$ and $\left.{ }^{18} \mathrm{O}^{12} \mathrm{C}^{16} \mathrm{O}\right)$ near $2.04 \mu \mathrm{m}$ for the in situ laser sensing of the Martian atmosphere, J. Quant Spectrosc. Radiat. Transfer 2006; 98: 264-76, doi 10.1016/j.jqsrt.2005.05.089.

[70] Predoi-Cross A, Luo C, Berman R, Drummond JR, May AD. Line strengths, selfbroadening, and line mixing in the $2000 \leftarrow 0110(\Sigma \leftarrow \Pi)$ Q branch of carbon dioxide, J. Chem Phys. 2000; 112: 8367-77.

[71] Gross LA, Griffiths PR. Pressure and temperature dependence of the selfbroadened linewidths of the carbon dioxide laser bands, Appl. Opt. 1987; 26: $2250-5$.

[72] Dana V, Valentin A. Determination of line parameters from FTS spectra, Appl. Opt. 1988; 27: 4450-3.

[73] Casa G, Wehr R, Castrillo A, Fasci E, Gianfran L. The line shape problem in the near-infrared spectrum of self-colliding $\mathrm{CO}_{2}$ molecules: Experimental investigation and test of semiclassical models, J. Chem. Phys. 2009; 130: 184306, doi 10.1063/1.3125965.

[74] Ely R, McCubbin J, T. K., The Temperature Dependence of the Self-Broadened Half-Width of the P-20 Line in the 001-100 Band of $\mathrm{CO}_{2}$, Appl. Opt. T. K. ; 9: 1230-1.

[75] Fanjoux G, Lavorel B, Millot G. Collisional Shifting and Broadening Coefficients for the Rovibrational Anisotropic lines of the $v_{1} / 2 v_{2}$ Fermi Dyad in $\mathrm{CO}_{2}$ Gas Studied by Stimulated Raman Spectroscopy, J. Raman Spectrosc. 1998; 29: 3917.

[76] Farooq A, Jeffries JB, Hanson RK. $\mathrm{CO}_{2}$ concentration and temperature sensor for combustion gases using diode-laser absorption near $2.7 \mu \mathrm{m}$, Appl. Phys. B: Lasers and Optics 2008; 90: 619-28, doi 10.1007/s00340-007-2925-y.

[77] Mihalcea RM, Baer DS, Hanson RK. Diode-laser absorption measurements of $\mathrm{CO}_{2}$ near $2.0 \mu \mathrm{m}$ at elevated temperatures, Appl. Opt. 1998; 37: 8341-7.

[78] Mandin J-Y, Dana V, Allout M-Y, Régalia L, Barbe A, Plateaux J-J. Line Intensities and Self-Broadening Coefficients in the 10012-10001 Band of ${ }^{12} \mathrm{C}^{16} \mathrm{O}_{2}$ Centered at $2224.657 \mathrm{~cm}^{-1}$, J. Mol. Spectrosc. 1995; 170: 604-7.

[79] Zéninari V, Vicet A, Parvitte B, Joly L, Durry G. In situ sensing of atmospheric $\mathrm{CO}_{2}$ with laser diodes near $2.05 \mu \mathrm{m}$ : a spectroscopic study, Infrared Phys. \& Tech. 2004; 45: 229-37, doi 10.1016/j.infrared.2003.11.004.

[80] Delière Q, Fissiaux L, Lepère M. Absolute line intensities and self-broadening coefficients in the $v_{3}-v_{1}$ band of carbon dioxide, J. Mol. Spectrosc. 2012; 272: 36-42, doi 10.1016/j.jms.2012.01.002.

[81] Tubbs LD, Williams D. Broadening of Infrared Absorption Lines at Reduced Temperatures: Carbon Dioxide, J. Opt. Soc. Am. 1972; 62: 284-9,. 
[82] Menzies RT, Tratt DM. Differential laser absorption spectrometry for global profiling of tropospheric carbon dioxide: selection of optimum sounding frequencies for high-precision measurements, Appl. Opt. 2003; 42: 6569-77.

[83] Aronson JR, von Thüna PC, Butler JF. Tunable Diode Laser High Resolution Spectroscopic Measurements of the $v_{2}$ Vibration of Carbon Dioxide, Appl. Opt. 1975; 14: 1120-7.

[84] Abrams RL. Broadening coefficients for the $\mathrm{P}(20) \mathrm{CO}_{2}$ laser transition, Appl. Phys. Lett. 1974; 25: 609-11, doi 10.1063/1.1655330.

[85] Webber ME, Kim S, Sander ST, Baer DS, Hanson RK, Ikeda Y. In situ combustion measurements of $\mathrm{CO}_{2}$ by use of a distributed-feedback diode-laser sensor near $2.0 \mu \mathrm{m}$, Appl. Opt. 2001; 40: 821-8.

[86] Le Barbu T, Parvitte B, Zéninari V, Vinogradov I, Korablev O, Durry G. Diode laser spectroscopy of $\mathrm{H}_{2} \mathrm{O}$ and $\mathrm{CO}_{2}$ in the $1.877-\mu \mathrm{m}$ region for the in situ monitoring of the Martian atmosphere, Appl. Phys. B: Lasers and Optics 2006; 82: 133-40, doi 10.1007/s00340-005-2020-1.

[87] Wallace CJ, Jeon C, Anderson CN, Havey DK. $\mathrm{H}_{2} \mathrm{O}$ Broadening of a $\mathrm{CO}_{2}$ Line and Its Nearest Neighbors Near $6360 \mathrm{~cm}^{-1}$, J. Phys. Chem. A 2011; 115: 1380410, doi 10.1021/jp208800s.

[88] Cousin C, Le Doucen R, Houdeau JP, Boulet C, Henry A. Air broadened linewidths, intensities, and spectral line shapes for $\mathrm{CO}_{2}$ at $4.3 \mu \mathrm{m}$ in the region of the AMTS instrument, Appl. Opt. 1986; 25: 2434-9.

[89] Cai T, Gao G, Gao X, Chen W, Liu G. Diode laser measurement of line strengths and air-broadening coefficients of $\mathrm{CO}_{2}$ and $\mathrm{CO}$ in the $1.57 \mu \mathrm{m}$ region for combustion diagnostics, Mol. Phys. 2010; 108: 539-45, doi 10.1080/00268970903547934.

[90] Corsi C, D'Amato F, De Rosa M, Modugno G. High-resolution investigation of the weak $v_{1}+3 v_{2}{ }^{1}-v_{2}{ }^{1}+v_{3}$ band of $\mathrm{CO}_{2}$ around $2 \mu \mathrm{m}$, Appl. Phys. B: Lasers and Optics 2000; 70: 879-81.

[91] Hörner G, Lau S, Kantor Z, Löhmannsröben H-G. Isotope selective analysis of $\mathrm{CO}_{2}$ with tunable diode laser (TDL) spectroscopy in the NIR, The Analyst 2004; 129: 772-8, doi $10.1117 / 10.1039 / b 404552 c$.

[92] Li JS, Durry G, Cousin J, Joly L, Parvitte B, Zéninari V. Self-induced pressure shift and temperature dependence measurements of $\mathrm{CO}_{2}$ at $2.05 \mu \mathrm{m}$ with a tunable diode laser spectrometer, Spectrochimica Acta 2012; A 85: 74- 8, doi 10.1016/j.saa.2011.09.016.

[93] Abubakar MS, Shaw JH. Carbon dioxide band intensities and linewidths in the 8 $12 \mu \mathrm{m}$ region, Appl. Opt. 1986; 25: 1196-203.

[94] Henry A, Dahoo P, Valentin A. Line strengths and self-broadening parameters of the ${ }^{12} \mathrm{C}^{16} \mathrm{O}_{2}(1001)_{\mathrm{I}} \leftarrow(1000)_{\text {II }}$ transition, Appl. Opt. 1986; 25: 3516-9.

[95] Rank DH, Fink U, Wiggins TA. Measurements on spectra of gases of planetary interest II. $\mathrm{H}_{2}, \mathrm{CO}_{2}, \mathrm{NH}_{3}$, and $\mathrm{CH}_{4}$, Astrophys. J. 1971; 143: 980-8.

[96] Arié E, Lacome N, Lévy A. Measurement of $\mathrm{CO}_{2}$ line broadening in the 10.4- $\mu \mathrm{m}$ laser transition at low temperatures, Appl. Opt. 1987; 26: 1636-40,.

[97] Valero FPJ, Suárez CB. Intensities and Half-WIdths at Different Temperatures for the $201_{\text {III }} \leftarrow 000$ Band of $\mathrm{CO}_{2}$ at $3854 \mathrm{~cm}^{-1}$, J. Quant. Spectrosc. Radiat. Transfer 1979; 22: 93-9. 
[98] McCubbin TK, Mooney TR. A Study of the Strengths and Widths of Lines in the 9.4 and $10.4 \mu \mathrm{m} \mathrm{CO}_{2}$ Bands, J. Quant Spectrosc. Radiat. Transfer 1968; 8: 125564.

[99] Tettemer GL, Planet WG. Intensities And Pressure- Broadened Widths Of $\mathrm{CO}_{2} R$ Branch Lines At $15 \mu \mathrm{m}$ From Tunable Laser Measurements., J. Quant. Spectrosc. Radiat. Transfer 1980; 24: 343-5.

[100] Planet WG, Tettemer GL, Knoll JS. Temperature Dependence Of Intensities And Widths Of $\mathrm{N}_{2}$-Broadened Lines in The $15 \mu \mathrm{m}$. $\mathrm{CO}_{2}$ Band From Tunable Laser Measurements, J. Quant. Spectrosc. Radiat. Transfer 1978; 20: 547-56.

[101] Saint-Loup R, Lavorel B, Millot G, Wegner C, Berger H. Enhancement of Sensitivity in High-Resolution Stimulated Raman Spectroscopy of Gases: Application to the $2 v_{2}\left(1285 \mathrm{~cm}^{-1}\right)$ Band of $\mathrm{CO}_{2}$, J. Raman Spectrosc. 1990; 21: 77-83.

[102] Gambetta A, Gatti D, Castrillo A, Galzerano G, Laporta P, Gianfrani L, Marangoni M. Mid-infrared quantitative spectroscopy by comb-referencing of a quantum-cascade-laser: Application to the $\mathrm{CO}_{2}$ spectrum at $4.3 \mu \mathrm{m}$, Appl. Phys. Lett. 2011; 99: 251107, doi 10.1063/1.3671081.

[103] Suárez CB, Valero FPJ. Temperature Dependence of Self-Broadened Half-widths of $\mathrm{CO}_{2}$, J. Quant. Spectrosc. Radiat. Transfer 1990; 43: 327-34.

[104] Brownsword RA, Salh JS, Smith IWM. Collision Broadening of $\mathrm{CO}_{2}$ Transitions in the Region of $4.3 \mu \mathrm{m}$ Effects of Broadening Gas (He, Ar, $\mathrm{N}_{2}$ ), Rovibrational States and Temperature, J. Chem. Soc. Faraday Trans. 1995; 91: 191-5.

[105] Predoi-Cross A, May AD, Vitcu A, Drummond JR, Hartmann J-M, Boulet C. Broadening and line mixing in the $20^{0} 0 \leftarrow 01^{1} 0,11^{1} 0 \leftarrow 00^{0} 0$ and $12^{2} 0 \leftarrow 01^{1} 0 \mathrm{Q}$ branches of carbon dioxide: Experimental results and energy-corrected sudden modeling, J. Chem. Phys. 2004; 120: 10520-9, doi 10.1063/1.1738101.

[106] Young C, Chapman RE. Line-widths and band strengths for the 9.4- and 10.4- $\mu \mathrm{m}$ $\mathrm{CO}_{2}$ bands, J. Quant. Spectrosc. Radiat. Transfer 1974; 14: 679-90.

[107] Dana V, Mandin J-Y, Guelachvili G, Kou Q, Morillion-Chapey M, Wattson RB, Rothman LS. Intensities and Self- Broadening Coefficients of ${ }^{12} \mathrm{C}^{16} \mathrm{O}_{2}$ Lines in the Laser Band Region, J. Mol. Spectrosc. 1992; 152: 328-41.

[108] Arié E, Lacome N, Arcas P, Levy A. Oxygen- and air-broadened linewidths of $\mathrm{CO}_{2}$, Appl. Opt. 1986; 25: 2584-91.

[109] Toth RA. Wavenumbers, strengths, and self-broadened widths of CO2 at $3 \mu \mathrm{m}, \mathrm{J}$. Mol. Spectrosc. 1974; 53: 1-14, doi http://dx.doi.org/10.1016/00222852(74)90256-2.

[110] Ghysels M, Durry G, Amarouche N. Pressure-broadening and narrowing coefficients and temperature dependence measurements of $\mathrm{CO}_{2}$ at $2.68 \mu \mathrm{m}$ by laser diode absorption spectroscopy for atmospheric applications, Spectrochimica Acta Part A: Molecular and Biomolecular Spectroscopy 2013; 107: 55-61, doi http://dx.doi.org/10.1016/j.saa.2013.01.042.

[111] Drayson SR, Young C. Band Strength and Line Half-Width of the $10.4 \mu \mathrm{CO}_{2}$ Band, J. Quant Spectrosc. Radiat. Transfer 1967; 7: 993-5.

[112] Geng J, Lunine JI, Atkinson GH. Absolute intensities and pressure-broadening coefficients of $2-\mu \mathrm{m} \mathrm{CO}_{2}$ absorption features: intracavity laser spectroscopy, Appl. Opt. 2001; 40: 2551-60. 
[113] Toth RA, Brown LR, Miller CE, Malathy Devi V, Benner DC. Spectroscopic database of $\mathrm{CO}_{2}$ line parameters: $4300-7000 \mathrm{~cm}^{-1}$, J. Quant. Spectrosc. Radiat. Transfer 2008; 109: 906-21, doi 10.1016/j.jqsrt.2007.12.004.

[114] Gamache RR, Hartmann J-M. An intercomparison of measured pressurebroadening and pressure-shifting parameters of water vapor, Can. J. Chem. 2004; 82: 1013-27.

[115] Gamache RR, Lamouroux J, Laraia AL, Hartmann J-M, Boulet C. Semiclassical calculations of half-widths and line shifts for transitions in the $30012 \leftarrow 00001$ and $30013 \leftarrow 00001$ bands of $\mathrm{CO}_{2}$ I: Collisions with $\mathrm{N}_{2}$, J. Quant. Spectrosc. Radiat. Transfer 2012; 113: 976-90, doi 10.1016/j.jqsrt.2012.02.014.

[116] Lamouroux J, Gamache RR, Laraia AL, Hartmann J-M, Boulet C. Semiclassical calculations of half-widths and line shifts for transitions in the $30012 \leftarrow 00001$ and $30013 \leftarrow 00001$ bands of $\mathrm{CO}_{2}$ II: collisions with $\mathrm{O}_{2}$ and Air, J. Quant. Spectrosc. Radiat. Transfer 2012; 113: 991-1003, doi 10.1016/j.jqsrt.2012.02.015.

[117] Lamouroux J, Gamache RR, Laraia AL, Hartmann J-M, Boulet C. Semiclassical calculations of half-widths and line shifts for transitions in the $30012 \leftarrow 00001$ and $30013 \leftarrow 00001$ bands of $\mathrm{CO}_{2}$ III: self collisions, J. Quant. Spectrosc. Radiat. Transfer 2012; 113: 1536-46, doi 10.1016/j.jqsrt.2012.03.035.

[118] Hartmann J-M, Boulet C, Robert D. Collisional effects on molecular spectra : laboratory experiments and models, consequences for applications, Elsevier Science, Amsterdam, 2008.

[119] Gamache RR, Hartmann J-M, Rosenmann L. Collisional Broadening of WaterVapor Lines : I. A Survey of Experimental Results, J. Quant. Spectrosc. Radiat. Transfer 1994; 52: 481-99.

[120] Gamache RR, Arié E, Boursier C, Hartmann J-M. A Review of PressureBroadening and Pressure-Shifting of Spectral Lines of Ozone, Spectrochimica Acta 1998; A 54: 35-63.

[121] Moskalenko NI, Zotov OV. New experimental investigation and refinement of transmission function of carbon dioxide: Line parameters (in Russian), Fiz. Atmos. Okeana 1977; 13: 488-98.

[122] Gamache RR, Lamouroux J. The vibrational dependence of half-widths of $\mathrm{CO}_{2}$ transitions broadened by $\mathrm{N}_{2}, \mathrm{O}_{2}$, air, and $\mathrm{CO}_{2}$, J. Quant. Spectrosc. Radiat. Transfer 2012; 117: 93-103, doi 10.1016/j.jqsrt.2012.10.028

[123] Gamache RR, Hartmann J-M. Collisional parameters of $\mathrm{H}_{2} \mathrm{O}$ lines: effects of vibration, J. Quant. Spectrosc. Radiat. Transfer 2004; 83: 119-47, doi 10.1016/S0022-4073(02)00296-0.

[124] Gamache RR, Lamouroux J. Predicting accurate line shape parameters for $\mathrm{CO}_{2}$ transitions, J. Quant Spectrosc. Radiat. Transfer 2013; 130: 158-71, doi 10.1016/j.jqsrt.2013.05.021.

[125] Lisak D, Hodges JT, Ciuryło R. Comparison of semiclassical line-shape models to rovibrational $\mathrm{H} 2 \mathrm{O}$ spectra measured by frequency-stabilized cavity ring-down spectroscopy, Phys. Rev. A 2006; 73: 012507, doi 10.1103/PhysRevA.73.012507.

[126] D’Eu J-F, Lemoine B, Rohart F. Infrared HCN Lineshapes as a Test of Galatry and Speed-Dependent Voigt Profiles, J. Mol. Spectrosc. 2002; 212: 96-110. 
[127] Ngo NH, Tran H, Gamache RR, Hartmann J-M. Pressure effects on water lines: beyond the Voigt profile, Phil. Trans. R. Soc. A 2012; 370: 2495-508 doi 10.1098/rsta.2011.0272.

[128] Birnbaum G. Microwave Pressure Broadening and its Application to Intermolecular Forces, Adv. in Chem. Phys. 1967; 12: 487-548.

[129] Bouanich J-P, Brodbeck C. Contribution des moments octupolaire et hexadecapolaire a l'elargissement des raies spectrales de molecules lineaires, J. Quant. Spectrosc. Radiat. Transfer 1974; 14: 141-51.

[130] Rogers RR, Yau MK. A Short Course in Cloud Physics, Butterworth Heinemann, Oxford, England, 1996.

[131] Wagner G, Birk M, Gamache RR, Hartmann J-M. Collisional parameters of $\mathrm{H}_{2} \mathrm{O}$ lines: effects of temperature, J. Quant. Spectrosc. Radiat. Transfer 2005; 92: 211 30 .

[132] Gamache RR, Laraia AL, Lamouroux J. Half-widths, their temperature dependence, and line shifts for the $\mathrm{HDO}-\mathrm{CO}_{2}$ system for applications to planetary atmospheres, Icarus 2011; 213: 720-30, doi 10.1016/j.icarus.2011.03.021.

[133] Varanasi P, Chudamani S. The temperature dependence of lineshifts, linewidths and line intensities of methane at low temperatures, J. Quant. Spectros. Radiat. Transfer 1990; 43: 1-11.

[134] Grossmann BE, Browell EV. Spectroscopy of Water Vapor in the 720-nm Wavelength Region: Line Strengths, Self-Induced Pressure Broadenings and Shifts, and Temperature Dependence of Linewidths and Shift, J. Mol. Spectrosc. 1989; 136: 264-94.

[135] Grossmann BE, Browell EV. Water-Vapor Line Broadening and Shifting by Air, Nitrogen, Oxygen, and Argon in the 720-nm Wavelength Region, J. Mol. Spectrosc. 1989; 138: 562-95.

[136] Gamache RR, Rothman LS, Temperature Dependence of Linewidths and Line Shifts, Paper O 26, Tenth Colloquium on High Resolution Molecular Spectroscopy, Dijon, France, 1987.

[137] Smith MAH, Rinsland CP, Devi VM, Benner DC. Temperature Dependence of Broadening and Shifts of Methane Lines in the $v_{4}$ Band, Spectrochimica Acta 1992; 48A: 1257-72.

[138] Frost BS. A theory of microwave lineshifts, J. Phys. B: Atom. Molec. Phys. 1976; 9: 1001-20.

[139] Devi VM, Benner DC, Smith MAH, Rinsland CP. Temperature dependence of Lorentz air-broadening and pressure-shift coefficients of 12CH4 lines in the 2.3$\mu \mathrm{m}$ spectral region, Journal of Quantitative Spectroscopy and Radiative Transfer 1994; 51: 439-65, doi 10.1016/0022-4073(94)90146-5.

[140] Smith MAH, Devi VM, Benner DC, Rinsland CP. Temperature Dependence of Air-Broadening and Shift Coefficients of $\mathrm{O}_{3}$ Lines in the $v_{1}$ Band, J. Mol. Spectrosc. 1997; 182: 239-59.

[141] Devi VM, Benner DC, Smith MAH, Rinsland CP. Air-Broadening and Shift Coefficients of $\mathrm{O}_{3}$ Lines in the $\mathrm{V}_{2}$ Band and Their Temperature Dependence, J. Mol. Spectrosc. 1997; 182: 221-38. 
[142] Birk M, Wagner G. Temperature-dependent air broadening of water in the 1250$1750 \mathrm{~cm}^{-1}$ range., J. Quant. Spectros. Radiat. Transfer 2012; 113: 889-928, doi 10.1016/j.jqsrt.2011.12.013. 


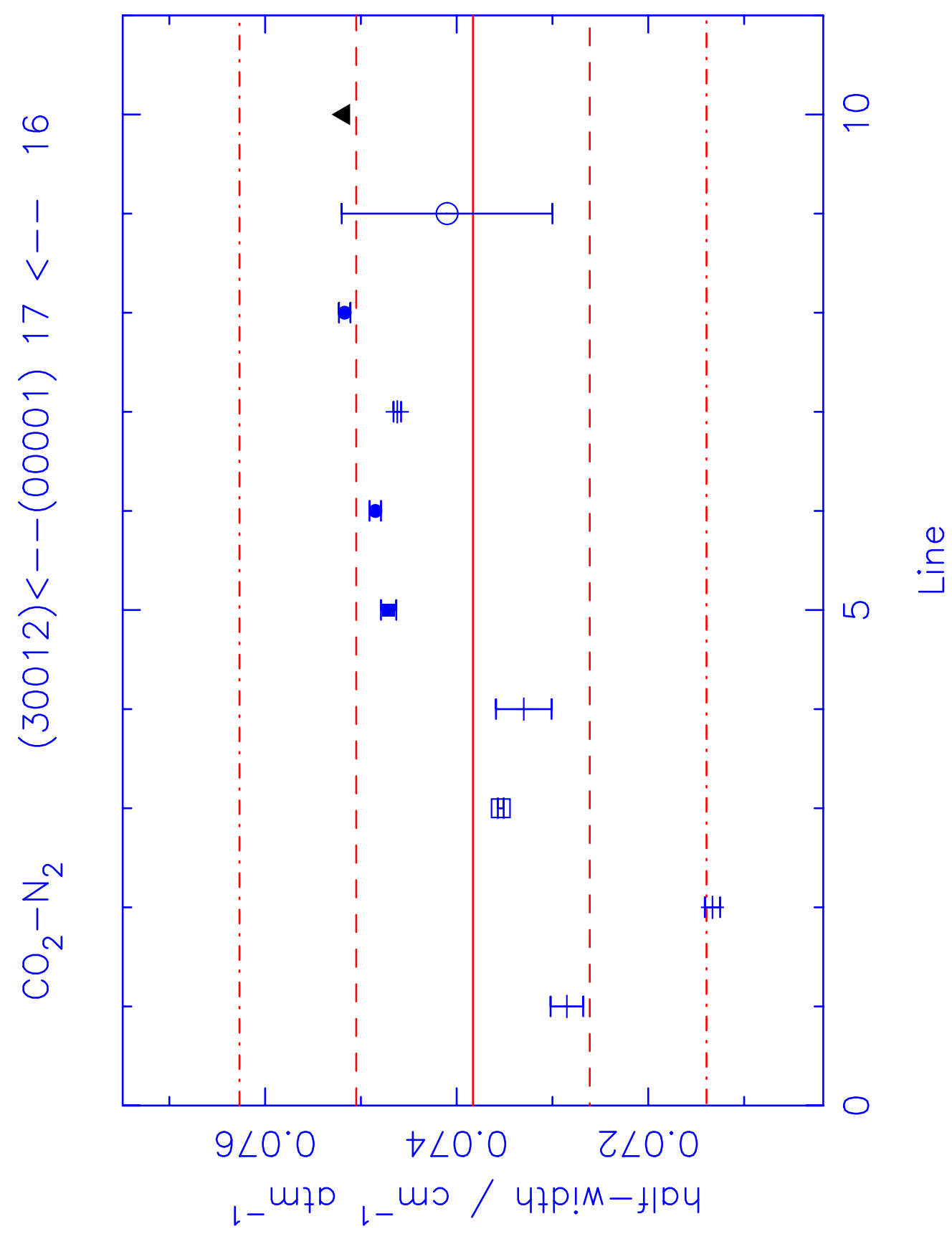

Figure 1 


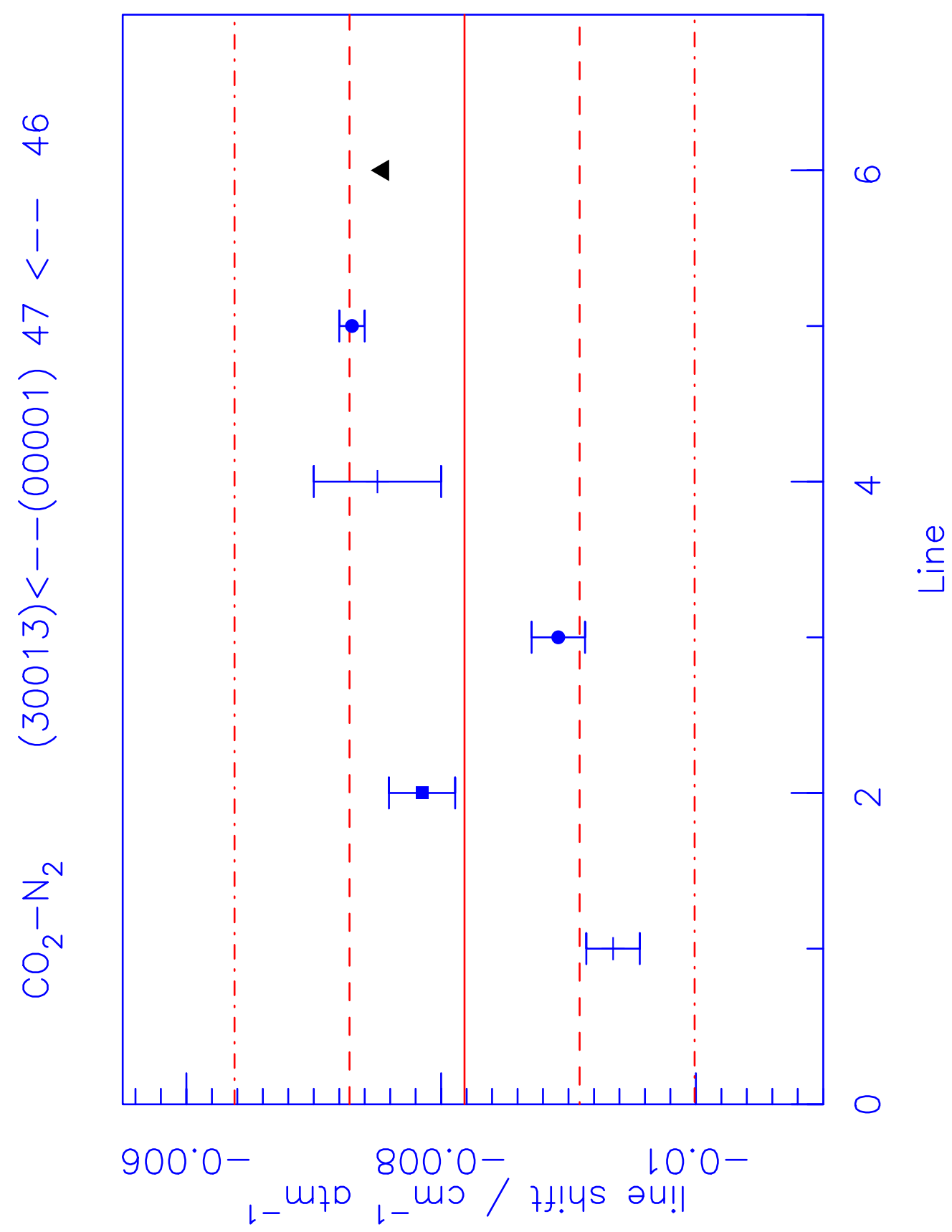

Figure 2 


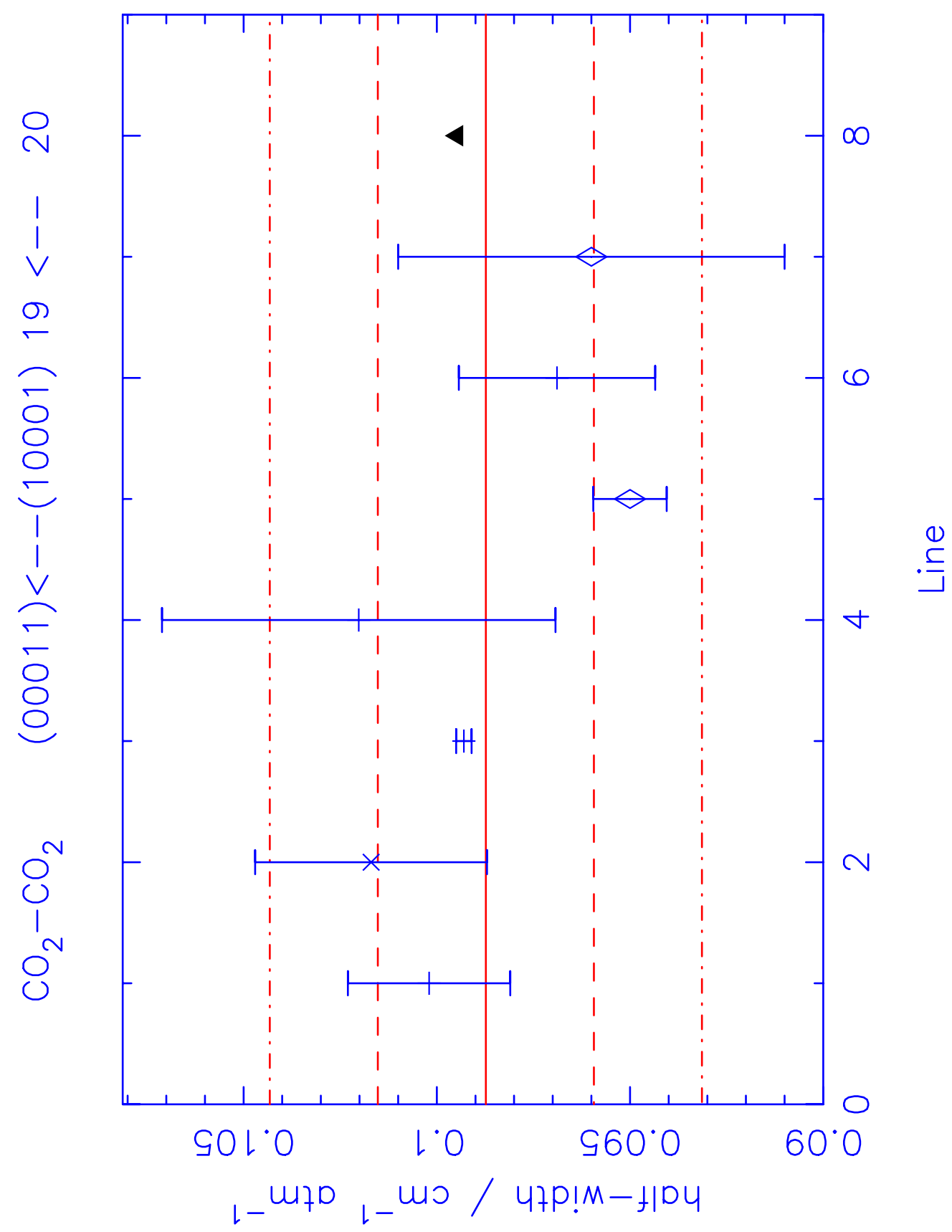

Figure 3 


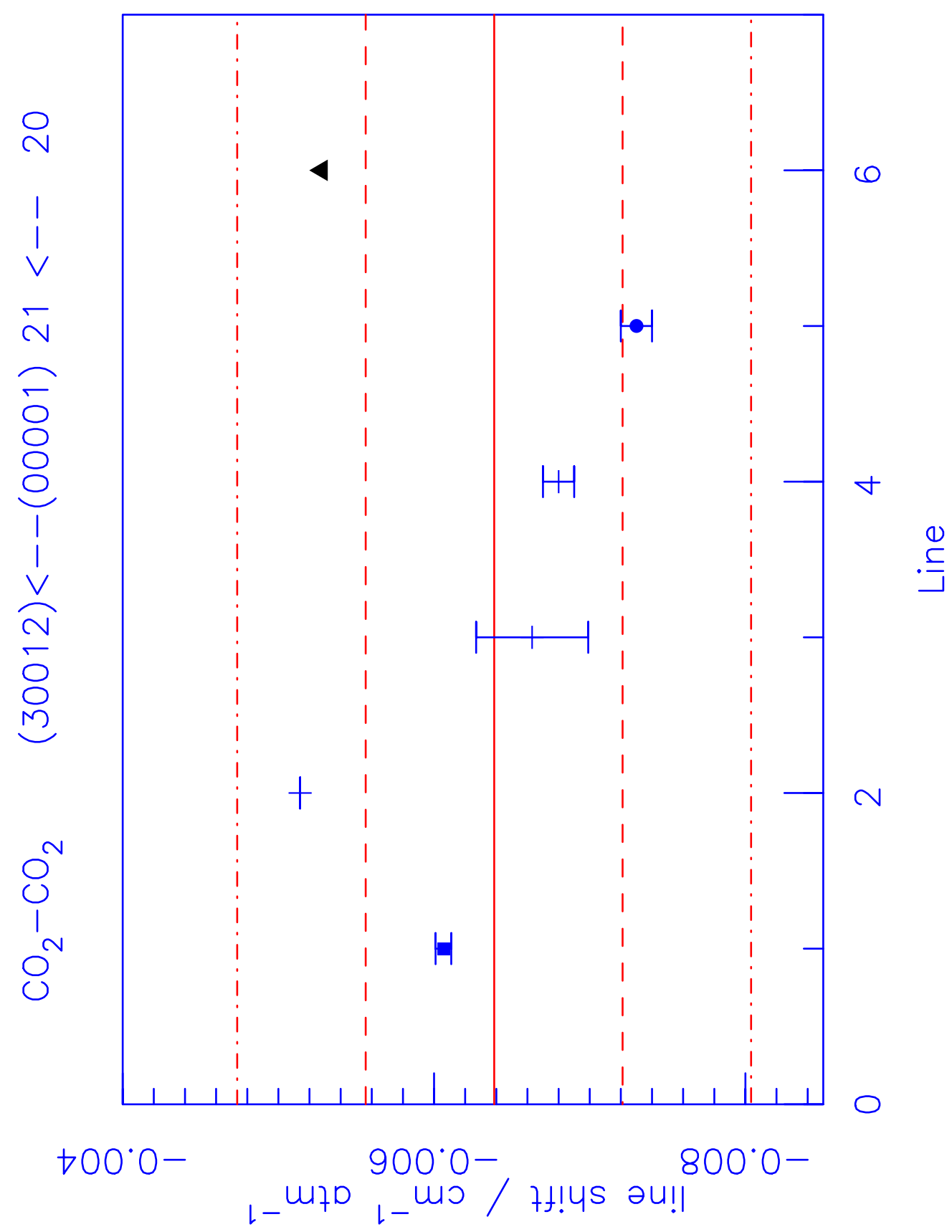

Figure 4 

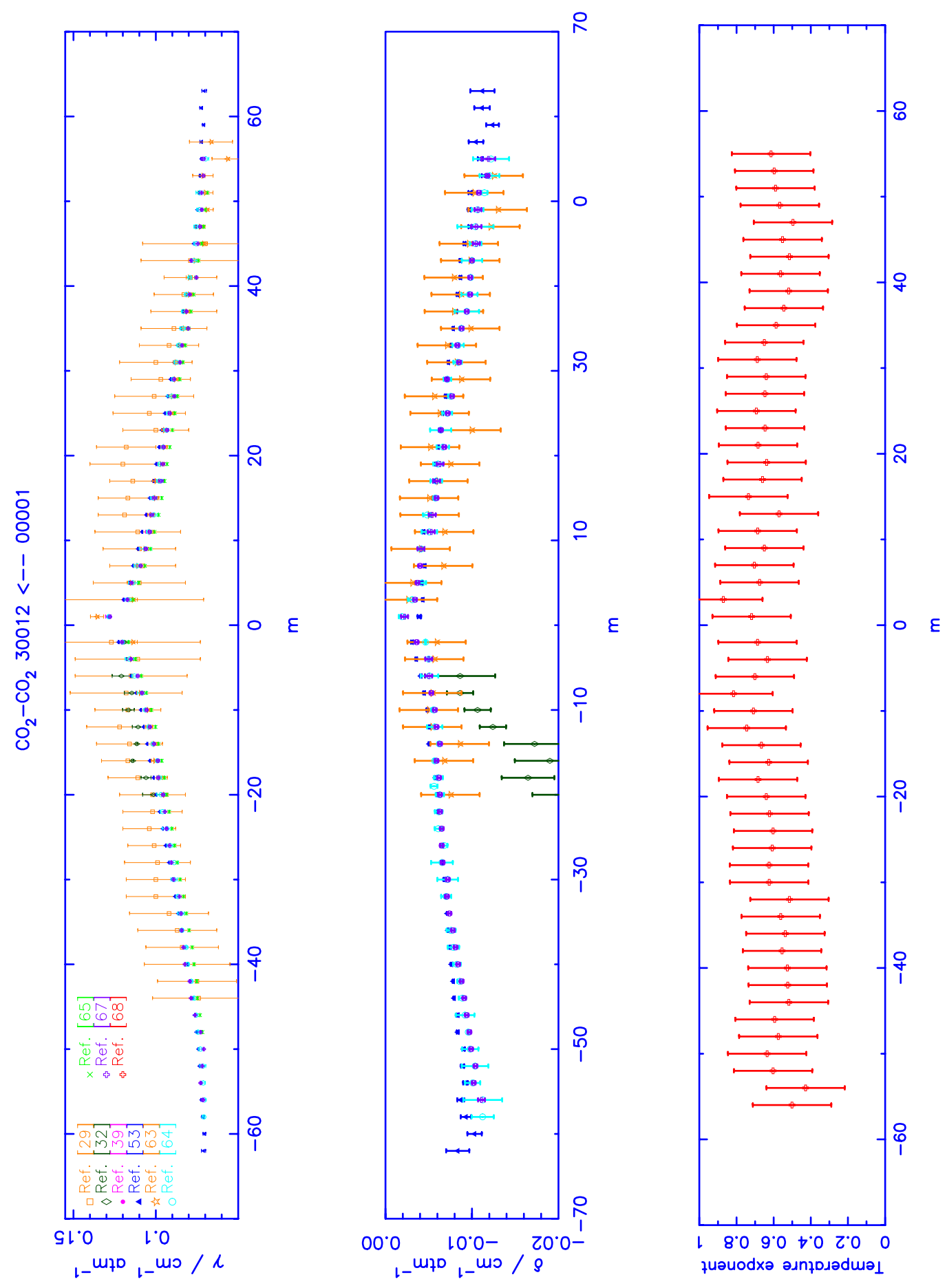

Figure 5 

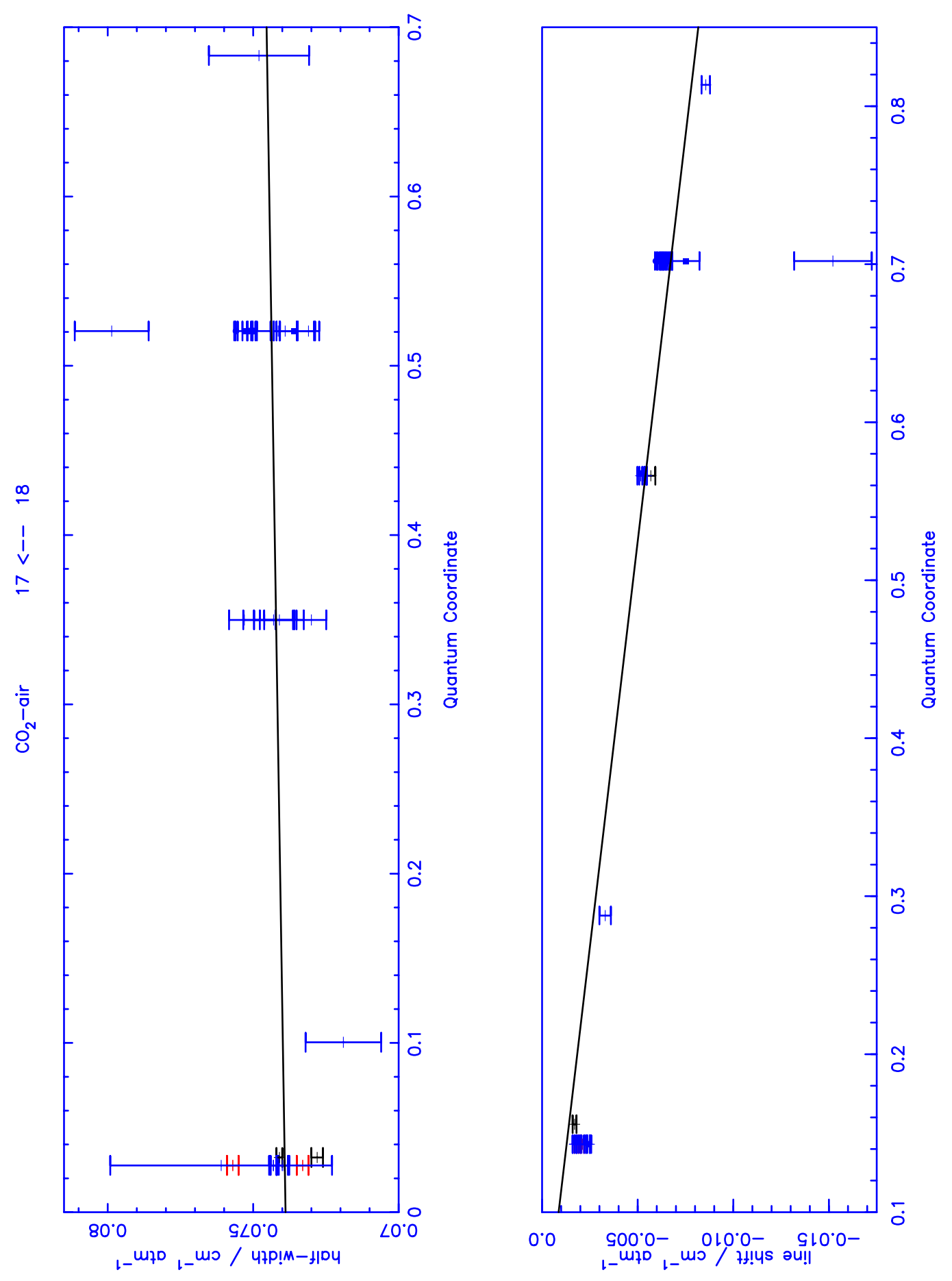

Figure 6 

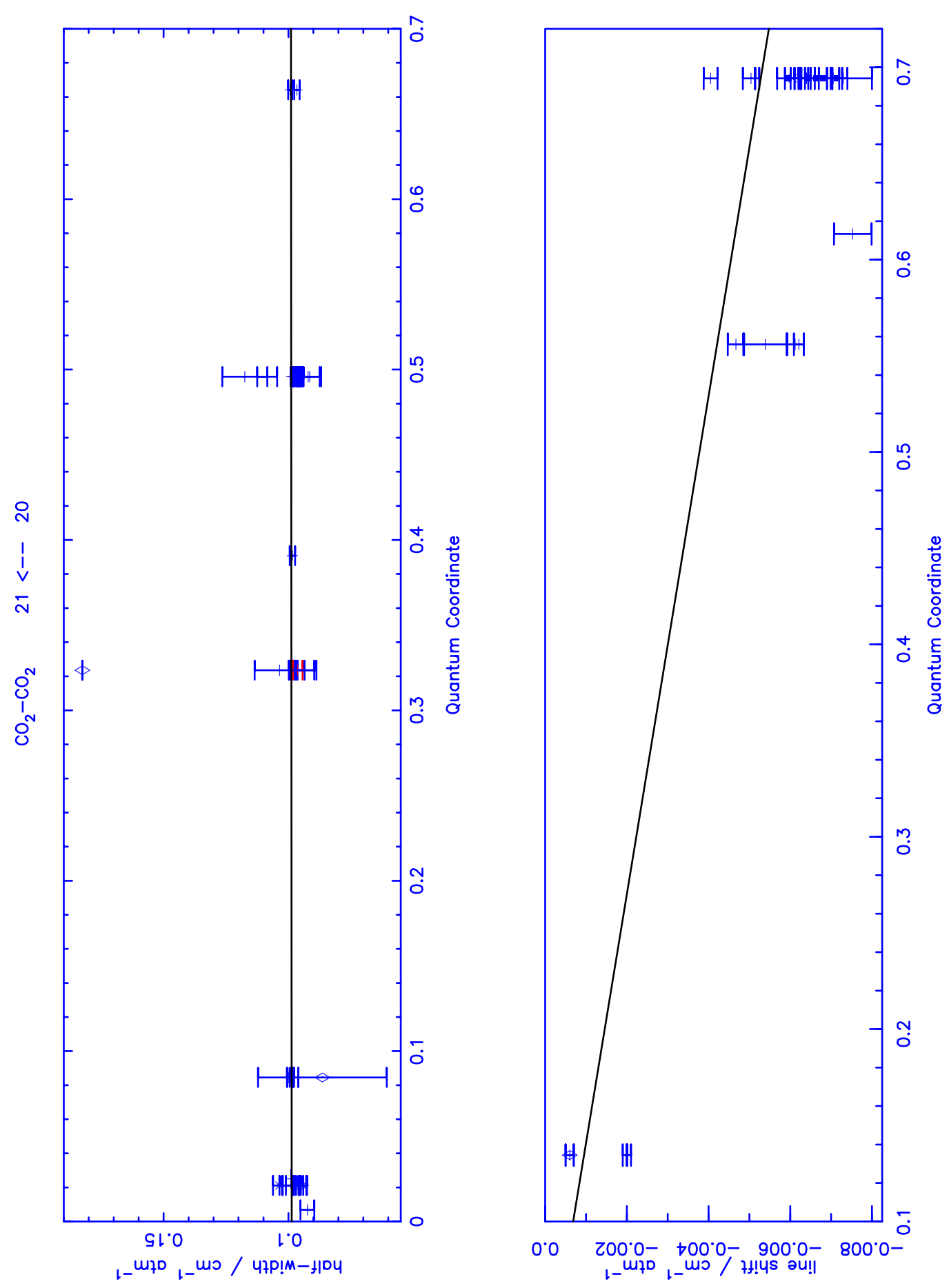

Figure 7 


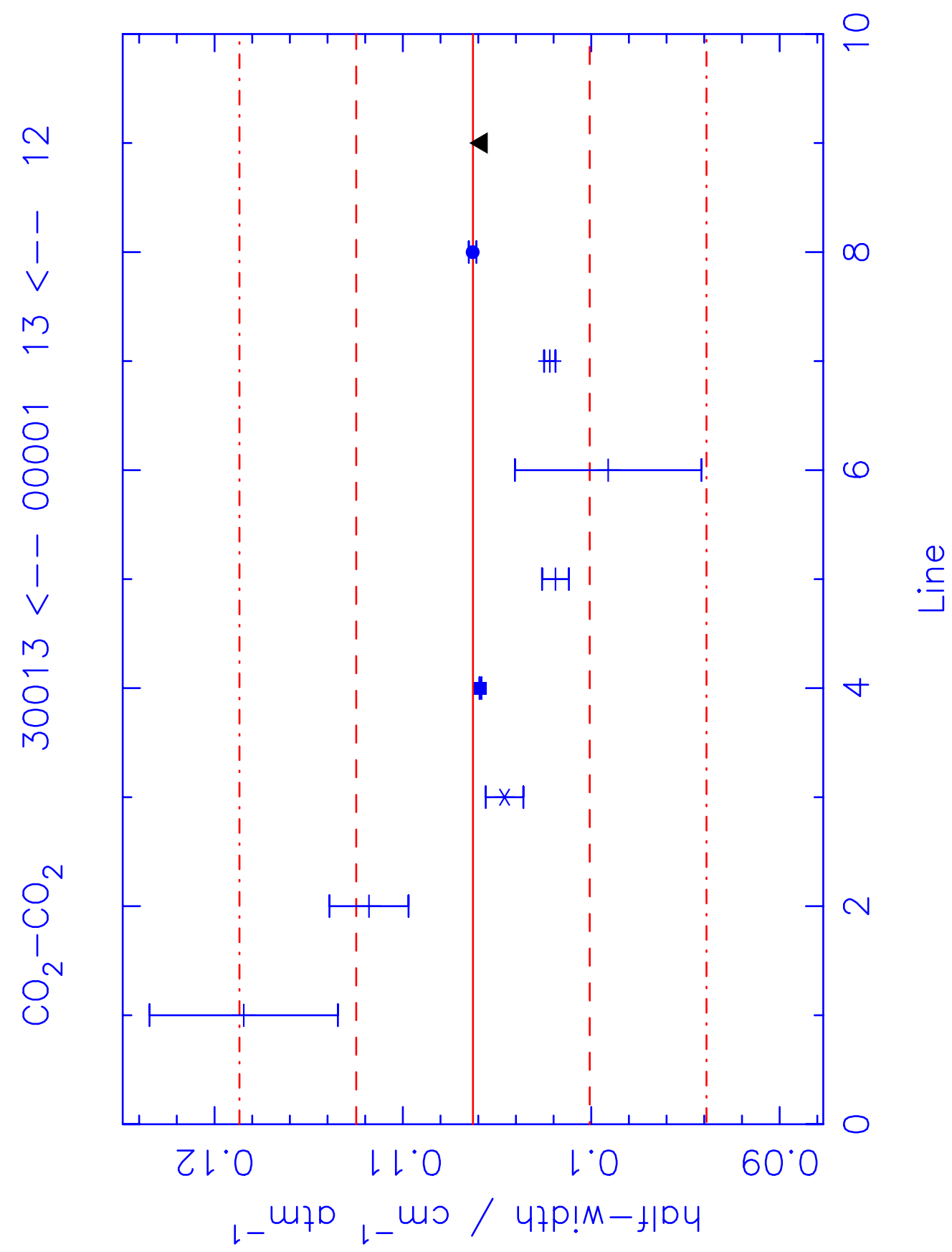

Figure 8 

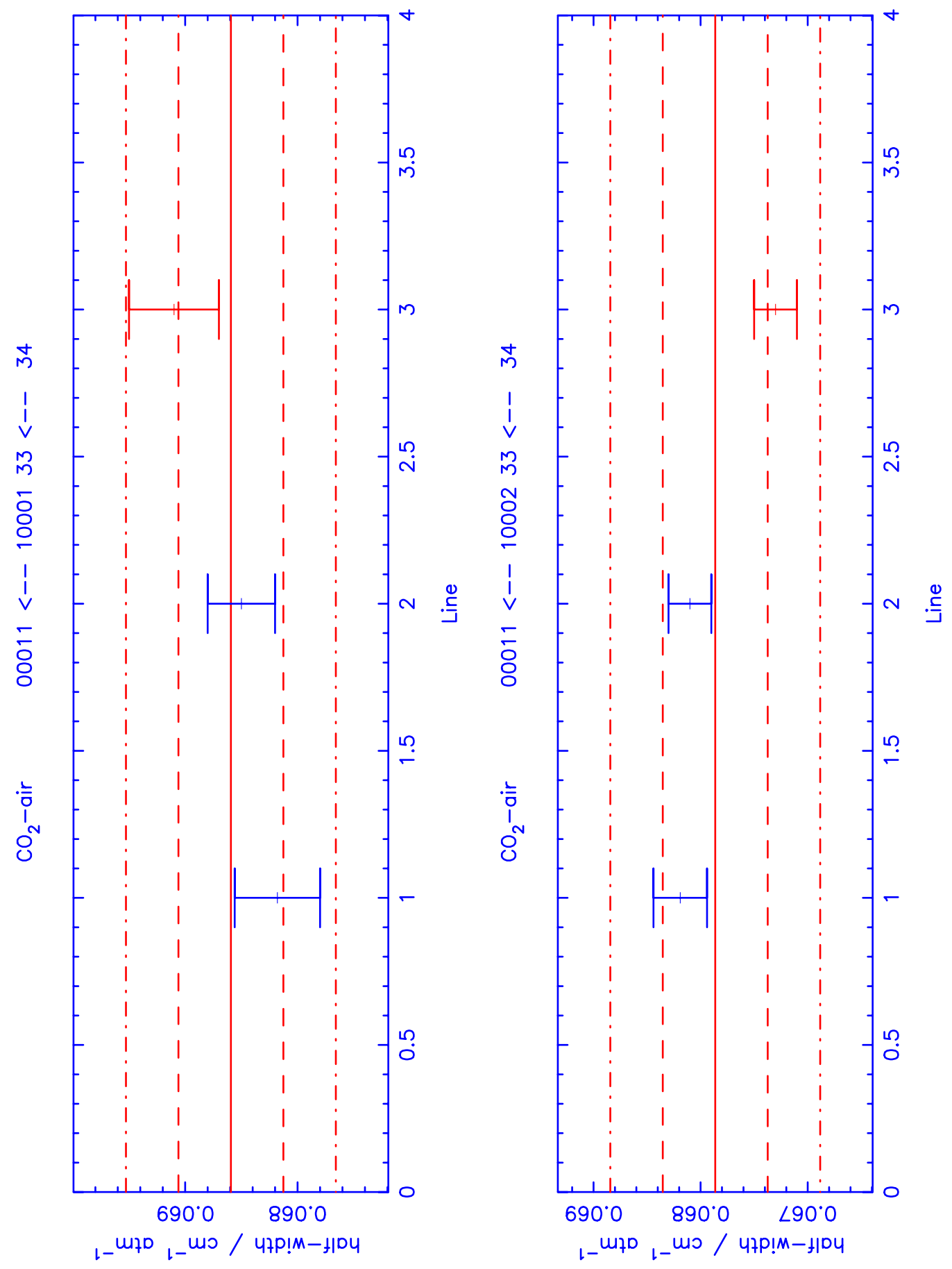

Figure 9 


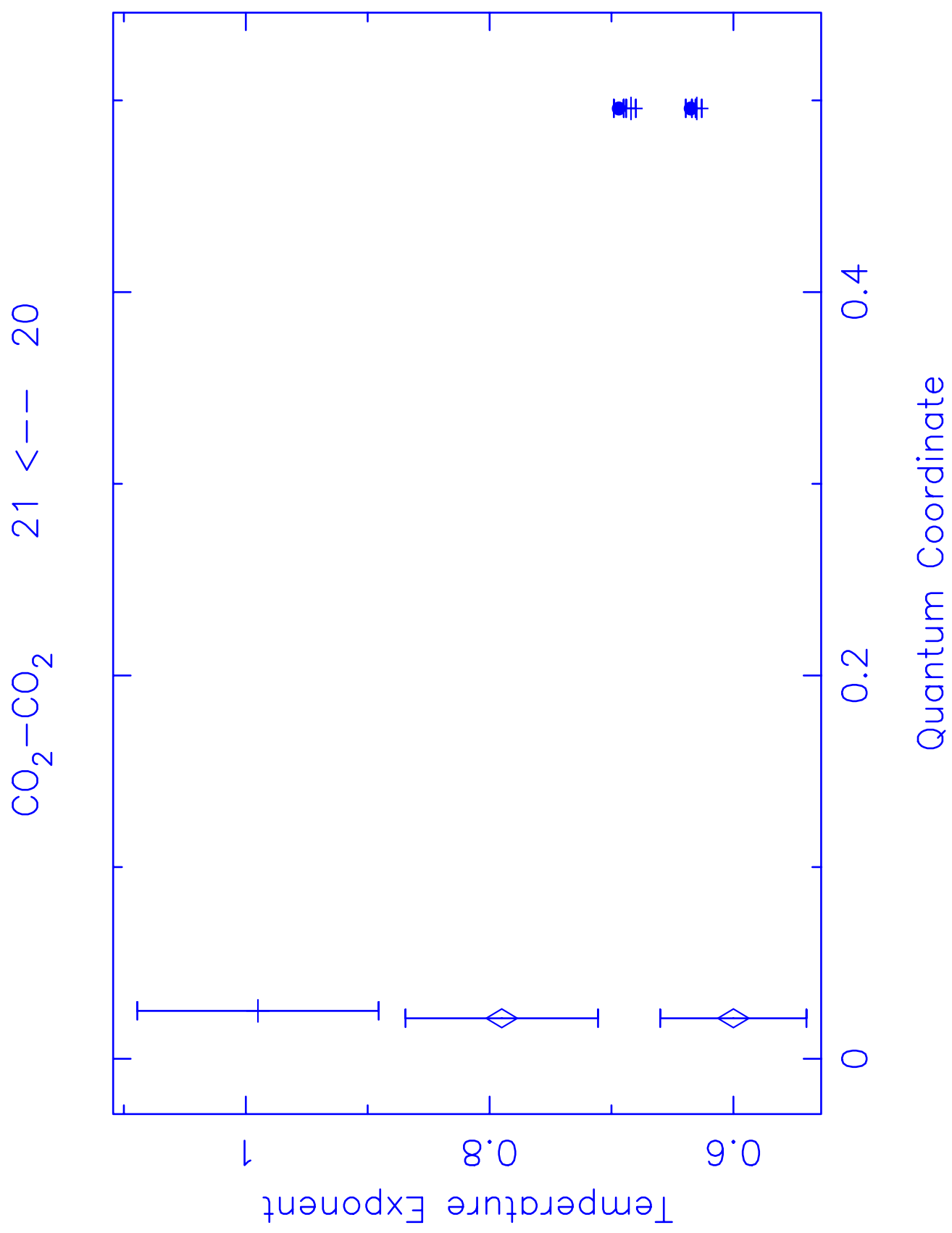

Figure 10 


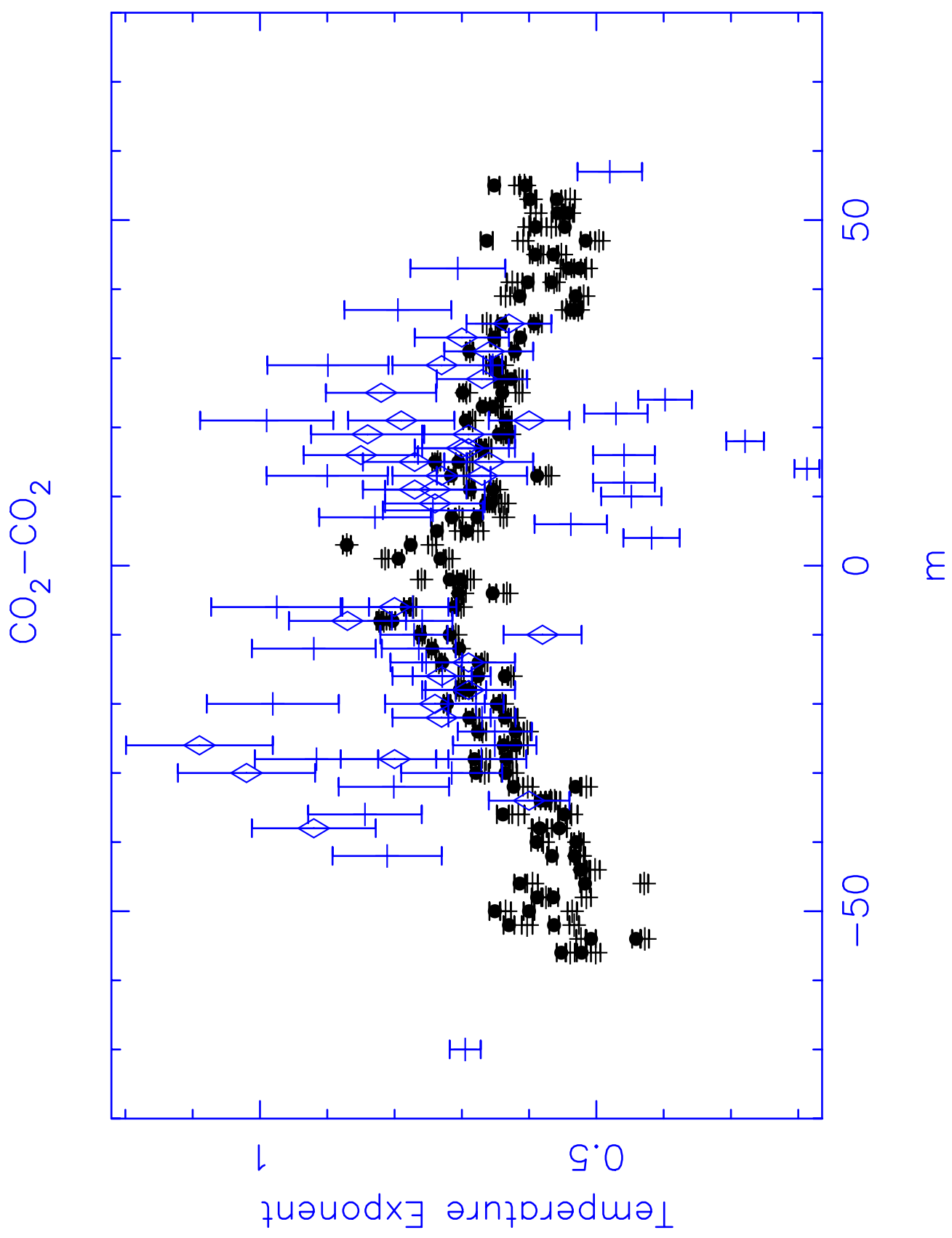

Figure 11 